\title{
Mood disorders in Huntington's disease: from behavior to cellular and molecular mechanisms
}

\author{
Patrick Pla ${ }^{1,2,3,4}$, Sophie Orvoen ${ }^{5}$, Frédéric Saudou ${ }^{1,2,3}$, Denis J. David ${ }^{5}$ and Sandrine Humbert ${ }^{1,2,3 *}$ \\ 1 Institut Curie, Orsay, France \\ ${ }^{2}$ CNRS UMR3306, Orsay, France \\ ${ }^{3}$ INSERM U1005, Orsay, France \\ ${ }^{4}$ Faculté des Sciences, Université Paris-Sud, Orsay, France \\ ${ }^{5}$ EA3544, Faculté de Pharmacie, Université Paris-Sud, Châtenay-Malabry, France
}

Edited by:

Benjamin Adam Samuels, Columbia

University, USA

\section{Reviewed by:}

Catherine Belzung, Université

Francois Rabelais, France

Emmanuel Brouillet, Commissariat à

I'Energie Atomique and Centre

National de la Recherche

Scientifique, France

*Correspondence:

Sandrine Humbert, Institut Curie, Bâtiment 110, 91405 Orsay Cedex, France

e-mail: sandrine.humbert@curie.fr
Huntington's disease (HD) is a neurodegenerative disorder that is best known for its effect on motor control. Mood disturbances such as depression, anxiety, and irritability also have a high prevalence in patients with HD, and often start before the onset of motor symptoms. Various rodent models of HD recapitulate the anxiety/depressive behavior seen in patients. HD is caused by an expanded polyglutamine stretch in the N-terminal part of a $350 \mathrm{kDa}$ protein called huntingtin (HTT). HTT is ubiquitously expressed and is implicated in several cellular functions including control of transcription, vesicular trafficking, ciliogenesis, and mitosis. This review summarizes progress in efforts to understand the cellular and molecular mechanisms underlying behavioral disorders in patients with HD. Dysfunctional HTT affects cellular pathways that are involved in mood disorders or in the response to antidepressants, including BDNF/TrkB and serotonergic signaling. Moreover, HTT affects adult hippocampal neurogenesis, a physiological phenomenon that is implicated in some of the behavioral effects of antidepressants and is linked to the control of anxiety. These findings are consistent with the emerging role of wild-type HTT as a crucial component of neuronal development and physiology. Thus, the pathogenic poly $\mathrm{Q}$ expansion in HTT could lead to mood disorders not only by the gain of a new toxic function but also by the perturbation of its normal function.

\section{Keywords: Huntington's disease, depression, anxiety, neurogenesis, Huntingtin, BDNF, serotonin, HPA axis}

\section{INTRODUCTION}

Huntington's disease (HD) is a fatal neurodegenerative disorder characterized by cognitive and psychiatric disturbances that are associated with loss of motor control, including chorea, dystonia, and a lack of gestural coordination (Novak and Tabrizi, 2011). These symptoms generally start to appear in midlife. A broad range of cognitive disturbances appear during HD progression. Early cognitive defects are characterized by poor adaptation and planification associated with deficits in executive functioning and perseveration. Other defects are most prevalent during the late stages of the disease, like learning difficulties and working and long term memory deficits, leading to dementia (Rosenblatt, 2007; Paulsen, 2011).

$\mathrm{HD}$ is caused by an abnormal expansion of glutamine (polyQ) in the N-terminal part of the $350 \mathrm{kDa}$ protein huntingtin (HTT). This stretch is encoded by a trinucleotide CAG repetition in exon 1 of HTT. An expansion greater than 36 repeats results in HD (Huntington Collaborative Research Group, 1993). The number of repeats is inversely correlated with the age of onset of motor symptoms and disease onset during childhood or adolescence is associated with more than 60 CAG repeats (Walker, 2007). HD is inherited in an autosomal dominant manner. Genetic and molecular studies have suggested that mutated polyQ-HTT leads to neuronal damage by gain of toxic function. The pathogenic mechanism requires the cleavage of full-length
HTT into smaller N-terminal fragments that contain the polyQ stretch that have been shown to be highly toxic in HD cellular and mouse models (Gafni et al., 2004; Graham et al., 2006). However, there is strong evidence that loss of the normal functions of wild-type HTT also plays a role in pathological mechanisms of HD.

\section{MOOD DISORDERS IN PATIENTS WITH HD}

Mood disturbances are prevalent not only among patients with diagnosed HD but also in pre-symptomatic carriers of the HD gene (Duff et al., 2007; Julien et al., 2007; Rosenblatt, 2007) (Table 1). These disturbances include impulsivity, irritability (which can be accompanied by aggressiveness), anxiety, and depression. Major depression is the most common symptom among pre-symptomatic HD carriers, although some patients will have only part of the symptoms of the major depression, or limited in intensity or time (Epping and Paulsen, 2011; Reedeker et al., 2012). Maniac depressive disorder is not particularly prevalent in HD (Van Duijn et al., 2008; Epping and Paulsen, 2011). Mood disturbances may precede the onset of the motor phenotype by $4-10$ years, making them one of the earliest symptoms of HD. The severity of depression in HD is not dependent on disease progression (Berrios et al., 2001; Craufurd et al., 2001; Kingma et al., 2008). This suggests that different mechanisms affect neurons involved in mood regulation and neurons involved in motor 
and cognitive skills that are disabled in late phases of the disease in HD patients. However, mood, and cognitive alterations may also share some pathogenic mechanisms as some aspects of these alterations are found associated in the general population and in HD patients. In particular, depression and memory impairments are observed together and this is also the case for cognitive flexibility and planification defects (Smith et al., 2012; Trivedi and Greer, 2014). Although apathy is part of symptoms of major depression, frequency, and intensity of apathy in HD patients increase with disease progression contrary to depression (Kingma et al., 2008; Van Duijn et al., 2010). Thus, as previously suggested (Levy et al., 1998), apathy appears not only as a symptom of depression but as a syndrome with its own dynamics and mechanisms.

The reasons underlying the frequent co-morbidity of HD and mood disorder are still unclear. Family history of HD, especially given that HD shows a dominant mode of inheritance, is probably an important factor. Indeed, an individual's knowledge that he or she is a carrier and will inevitably experience neurological symptoms, could contribute to the prevalence of psychiatric disturbances. However, this explanation alone is not sufficient to explain the high prevalence of psychiatric disturbances in HD (Almqvist et al., 2003; Julien et al., 2007; Van Duijn et al., 2008). Therefore, there are probably one or several molecular mechanisms, independent of the psychosocial environment, that can explain the prevalence of mood disorders in patients or carriers of HD. This hypothesis can be tested in animal models of HD.

There is no treatment that can halt or even slow down the progression of Huntington's disease. Current effective treatments aim to ease the symptoms of this disease. The evidence base for drugs in HD is very small so the choice of pharmacological agents is based mainly on clinical experience. Various molecules are used to treat motor dysfunction. These include neuroleptics for chorea, and tetrabenazine (which is a dopamine-depleting agent that inhibits the vesicular dopamine transporter VMAT2) for dyskinesia. Tetrabenazine is the most effective drug for the management of HD and hence is the first choice of treatment; however, this drug induces depression and sedation in patients (Frank, 2010; Mestre and Ferreira, 2012) and similar findings were reported in a mouse model of HD (YAC128) (Wang et al., 2010). Stress, anxiety, and depression can aggravate chorea, so measures to treat these mood problems may also help to slow the progression of HD. Mood disorders in HD are treated by antidepressant and/or anxiolytic drugs (Table 1). Pre-symptomatic HD carriers are almost twice as likely to be treated with antidepressants than individuals who are not carriers of HD (Rowe et al., 2012). At present, there is no established molecular evidence base for the treatment of depression in HD. However, antidepressants are often very effective in clinical practice (Novak and Tabrizi, 2011). Depression is most commonly treated with classic serotonin-specific reuptake inhibitors (SSRIs) such as citalopram or sertraline. Fluoxetine is often avoided as it exacerbates chorea and enhances anxiety, both of which frequently occur in patients with HD (Chari et al., 2003; Novak and Tabrizi, 2011). Anxiety is treated with non-stimulating SSRIs such as buspirone or benzodiazepines (Novak and Tabrizi, 2011).

\section{MOUSE MODELS OF HD}

Various rodent models have been used to study the effect of polyQ expansion in HTT (Heng et al., 2008; Pouladi et al., 2013). These models differ in the number of CAG repeats, the size of the expressed HTT fragment, and the gene promoter used. Thus, the amount of mutant HTT that is expressed varies between different models. The genetic background of the mouse strains used to design models of HD is also important, especially because various strains perform differently in behavioral tests (Miller et al., 2010; Mozhui et al., 2010). These models can be grouped according to their mode of expression of mutant HTT: transgenic models expressing truncated HTT, transgenic models expressing full-length HTT, and knock-in (KI) models.

The short lifespan of mouse models prevents them from developing the same neuropathological symptoms that develop during decades in human. Large numbers of glutamines in the polyQ stretch in the homozygous state in KI models and/or a high abundance of transgenic mutant proteins are necessary to obtain a robust phenotype. The length of the $\mathrm{N}$-terminal fragments and their toxicity are inversely correlated, which underlies the robust phenotype of models in which a short N-terminal polyQ-HTT fragment is expressed (Hackam et al., 1998; Landles et al., 2010).

The sequence coding the $350 \mathrm{kDa}$ HTT protein contains 67 exons spanning over $170 \mathrm{~kb}$ of the mouse genome. Hence, the creation of transgenic models in which full-length HTT is expressed is a difficult task. Therefore in some models, the exogenous protein is limited to the $\mathrm{N}$-terminal part containing the polyQ expansion, with the assumption that this portion is sufficient to recapitulate some aspects of the disease. R6/1 and R6/2 mice carry a transgene encompassing exon 1 of $\mathrm{Htt}$ (Mangiarini et al., 1996). In R6/1 mice this exon contains a polyQ tract of approximately 115 residues whereas in $\mathrm{R} 6 / 2$ mice this number is 150 . The progression of HD in R6/2 and R6/1 mice is particularly fast and aggressive, therefore these mice may only be suitable as models for juvenile $\mathrm{HD}$, which manifests in patients with very extensive polyQ stretches. These models could also correspond to the late HD stages when HTT is cleaved and N-terminal fragments accumulate. N171-82Q mice carry a transgene encompassing the first 171 amino acids of HTT with a polyQ tract of 82 residues (Schilling et al., 1999).

Transgenic models expressing full-length mutant HTT contain the human HTT gene with an expanded CAG repeat which is randomly inserted into the mouse genome through a Yeast Artificial Chromosome (YAC) or a Bacterial Artificial Chromosome (BAC). The YAC72 model contains full length HTT including $72 \mathrm{CAG}$ repeats and the YAC128 model contains full length HTT including 128 CAG repeats (Hodgson et al., 1999). Transgenic HTT in BACHD mice contains 97 CAG repeats coding for glutamine (Gray et al., 2008). In these models, transgenic HTT is under the control of the human HTT promoter. The endogenous wildtype form of HTT is still expressed in these models, which is also the case for models expressing a truncated form of HTT. Interestingly, mouse models expressing full-length mutant HTT generally develop motor deficits later than transgenic models with truncated HTT, which allows more time to study anxio-depressive behaviors without interference from motor impairment in these mice. 
Table 1 | Clinical observations on Huntington's disease patients.

\section{Clinical studies Psychiatric observations (number of patients)}

$32.8 \%$ had affective disorders

Age at onset of motor symptoms for persons with affective disorder was significantly later than that for persons without affective disorder (43.4 and 38.7 years, respectively).
217 patients with moto symptoms (comparison black vs. white patients)
$39 \%$ were depressed $16 \%$ had attempted suicide

$34 \%$ had suicidal ideation

\section{Scale used to assess depression and/or anxiety}

\section{Use of pharmacologic References treatments}

\section{DSM-III criteria}

ND

Folstein et al., 1987

Diagnostic Interview

Schedule
134 patients
Male subjects $=47 \%$
UHDRS

PBA-HD
$34 \%$ were given

antidepressant drugs.

$24 \%$ were given sedative

or anxiolytic treatment

\begin{tabular}{|c|c|c|c|c|}
\hline $\begin{array}{l}2835 \text { patients } \\
\text { Male subjects }=47.5 \%\end{array}$ & $\begin{array}{l}\text { More than } 40 \% \text { of patients have } \\
\text { depressive symptoms. } \\
\text { More than } 10 \% \text { have attempted suicide }\end{array}$ & UHDRS & $\begin{array}{l}\text { More than } 50 \% \text { had } \\
\text { received antidepressant } \\
\text { treatments in the past }\end{array}$ & Paulsen et al., 2005 \\
\hline
\end{tabular}

681 patients
Male subjects $=46 \%$

More psychiatric symptoms (e.g., depression, anxiety, obsessive-compulsiveness) than healthy people.

Higher levels of psychiatric symptoms in individuals with severe motor impairment

204 participants, blind to their genetic status, asymptomatic (definite HD were excluded)

254 at risk of $\mathrm{HD}$ or recently diagnosed participants Male subjects $=29 \%$
$20 \%$ had experienced major depression $17 \%$ had an anxiety disorder, and $11 \%$ had general anxiety.

The rate of depression increased as a function of proximity to clinical onset

\section{Increased anxiety score in} presymptomatic carriers and patients with $\mathrm{HD}$ individuals.

$\approx 25 \%$ of presymptomatic carriers and patients with HD were depressed Prevalence of symptoms increases with the progression of $\mathrm{HD}$.

\begin{tabular}{|c|c|c|c|c|}
\hline $\begin{array}{l}152 \text { patients, including } \\
\text { pre-symptomatic } \\
\text { Male subjects }=45.5 \%\end{array}$ & $\begin{array}{l}\text { Higher prevalence of depression in HD } \\
\text { patients, including pre-symptomatic. No } \\
\text { higher prevalence with development of } \\
\text { HD }\end{array}$ & PBA-HD & ND & Kingma et al., 2008 \\
\hline $\begin{array}{l}154 \text { patients including } \\
\text { pre-symptomatic carriers } \\
\text { Male subjects }=45.7 \%\end{array}$ & $\begin{array}{l}\text { Higher prevalence of depression/anxiety in } \\
\text { presymptomatic and symptomatic HD } \\
\text { patients than average population. }\end{array}$ & $\begin{array}{l}\text { DSM-IV criteria } \\
\text { CIDI }\end{array}$ & $\begin{array}{l}26.4 \% \text { were given } \\
\text { antidepressant treatment }\end{array}$ & Van Duijn et al., 2008 \\
\hline $\begin{array}{l}803 \text { prodromal patients } \\
\text { with HD mutation } \\
\text { Male subjects }=36 \%\end{array}$ & Depression prevalence higher in females. & $\begin{array}{l}\text { BDI-II } \\
\text { SCL-90-R } \\
\text { UHDRS }\end{array}$ & ND & Epping et al., 2013 \\
\hline
\end{tabular}

BDI-II, Beck Depression Inventory; CES-D, Center for Epidemiological Studies Depression Scale; CIDI, Composite International Diagnostic Interview; DSM-IIIIV, Diagnostic and Statistical Manual of Mental Disorders 3rd/4th edition; PBA-HD, Problem Behaviors Assessment for Huntington Disease; SCL-90-R, Symptom Checklist 90 Revised; UHDRS, Unified Huntington Disease Rating Scale; ND, no data. 
KI models are constructed by replacing the murine exon 1 of the endogenous $\mathrm{Htt}$ gene by a chimeric human/mouse sequence that includes various lengths of the CAG stretch (Menalled et al., 2009). Heterozygous KI HD mice thus mimic the genetic situation of human patients. KI models are also considered a more accurate genetic HD model than many transgenic models, because they express the mutated gene under the control of the endogenous mouse promoter. Thus, the mutated HTT is expressed at levels similar to the endogenous gene, and is not overexpressed as in transgenic models. This may explain why KI mice have a milder phenotype than that of transgenic mouse models. Indeed, KI strains present very little or subtle observable motor dysfunction, and a normal lifespan (Menalled et al., 2009). KI mouse models can be particularly useful to study the early symptoms of the disease, including anxio-depressive disorders, prior to the onset of motor impairments.

Few models have been developed to study the role of wildtype HTT. The knock-out of $\mathrm{Htt}$ is lethal early in development at embryonic day 7.5 (Duyao et al., 1995; Nasir et al., 1995; Zeitlin et al., 1995); therefore, Cre-Lox systems have been used to study the role of HTT in the developing nervous system or in the adult nervous system (Dragatsis et al., 2000; Dietrich et al., 2009; Pla et al., 2013). CaMKCreER ${ }^{T 2}$; Htt flox/flox mice were generated to study the function of HTT in mature cortical and hippocampal neurons of adult mice. Following tamoxifen injection (in 2 month old mice), $H t t^{\text {flox/flox }}$ is excised specifically from the genome of these neuronal cells, hence allowing the study of HTT function in adult mice without developmental bias (Pla et al., 2013). KI mice containing point mutations in $\mathrm{Htt}$ have also been produced to study the role of post-translational modifications of HTT. These models involve modifications of serines 1181 and 1201 that are phosphorylated by Cdk5: mutations either mimic constitutive phosphorylation or prevent phosphorylation at these two sites (Ben M’Barek et al., 2013).

\section{MOUSE MODELS OF HD PRESENT ANXIETY/DEPRESSIVE-LIKE PHENOTYPES}

The anxio-depressive status of various mouse models of HD has been investigated by classical behavioral tests. Results are summarized in Table 2 .

\section{ANXIETY PARADIGMS}

The open-field test is frequently used to assess motor activity but can also be applied to measure anxiety. During this test, mice are allowed to explore a walled enclosure for about $30 \mathrm{~min}$. Mice usually spend most of their time along the walls rather than in the middle of the field, because they fear that exposure may make them vulnerable to predators. Therefore, anxiety is inversely correlated with the amount of time the mouse spends in the center, and/or the number of trips it makes from the walls to the center. It is however necessary to verify that the behavioral differences between wild-type and HD mice in this test are not due to an impaired motility of the HD animals. This is particularly important because HD models (and especially the transgenic ones) develop impairment to motor behavior. With this in mind, the most pertinent variable to measure is the "ambulatory distance/total ambulatory distance" ratio. According to this variable, male $H d h$ Q111/Q111 mice and CaMKCreER ${ }^{T 2}$; Htflox/flox mice show an anxiety-like behavior (Orvoen et al., 2012; Pla et al., 2013). R6/2 mice and YAC128 mice also spend little time in the center of the area (Ciamei and Morton, 2008; Chiu et al., 2011). However, this finding may not be significant for YAC128 mice because they also travel short distances.

The elevated plus maze (EPM) test is based on the aversion of mice to open spaces and height, and is widely-used in the study of anxiety behaviors. In R6/1 mice, anxiety-like behavior appears progressively and reaches its peak in 24 week-old mice. However, this test is difficult to interpret at this age because locomotor activity is also altered. This impairment is shown by the small number of entries that the mouse makes into both the open and closed arms of the maze (Naver et al., 2003; Nithianantharajah et al., 2008). An anxiety phenotype is observed in YAC128 mice, which spend less time in the open quadrants of the zero-maze than in the closed quadrants (Chiu et al., 2011). An anxiety-like

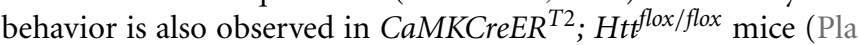
et al., 2013), showing that a loss of function of HTT only in mature cortical and hippocampal neurons in adults is sufficient to lead to anxiety.

The light/dark box test is used to assess anxiety-like behaviors and is based on the aversion of mice to light. Variables that are measured include the latency to enter the lit compartment, and the time spent in each compartment. Both male and female R6/2 mice exhibit an anxiety-like behavior from 12 to 14 weeks as assessed by this test. Anxiety may start earlier in males than in females, although this is not a consistent finding (Hickey et al., 2005; Menalled et al., 2009). Menalled and colleagues also showed that 12 week-old BACHD mice spend a long time in the dark box, indicative of an anxiety-like phenotype (Menalled et al., 2009). CAG140 mice show a high latency to enter the lit compartment at 1.5 months of age but not at 8 months of age (Hickey et al., 2008). This suggests that an early anxiety-like phenotype in both males and females disappears as the disease progresses. $H d h^{Q 111 / Q 111}$ or YAC128 mice display no phenotype in this test (Chiu et al., 2011; Orvoen et al., 2012).

\section{ANXIETY-DEPRESSIVE PARADIGMS}

The novelty suppressed feeding (NSF) test is a conflict test with competing motivations: the drive to eat and the fear of venturing into the center of a brightly lit area. This test measures both anxiety and depression and the outcome of this test is sensitive to anxiolytics and chronic antidepressants, but not to acute antidepressants (David et al., 2009). The NSF test is also described as a "neurogenesis-dependent" test, because the ablation of neurogenesis in the hippocampus blocks the efficacy of antidepressants in this test (David et al., 2009). R6/1, Hdh Q111/Q111, and CaMKCreER ${ }^{T 2} ; \mathrm{Htt}^{\text {flox/flox }}$ mice show a high latency to eat in the NSF paradigm, suggestive of anxiodepressive-like behavior in these mice (Renoir et al., 2011; Orvoen et al., 2012; Pla et al., 2013).

\section{DEPRESSIVE PARADIGMS}

The sucrose preference test is used to measure anhedonia, which is a component of depressive behavior in both humans and mice. Studies show that HD mice have a lower preference for sucrose 


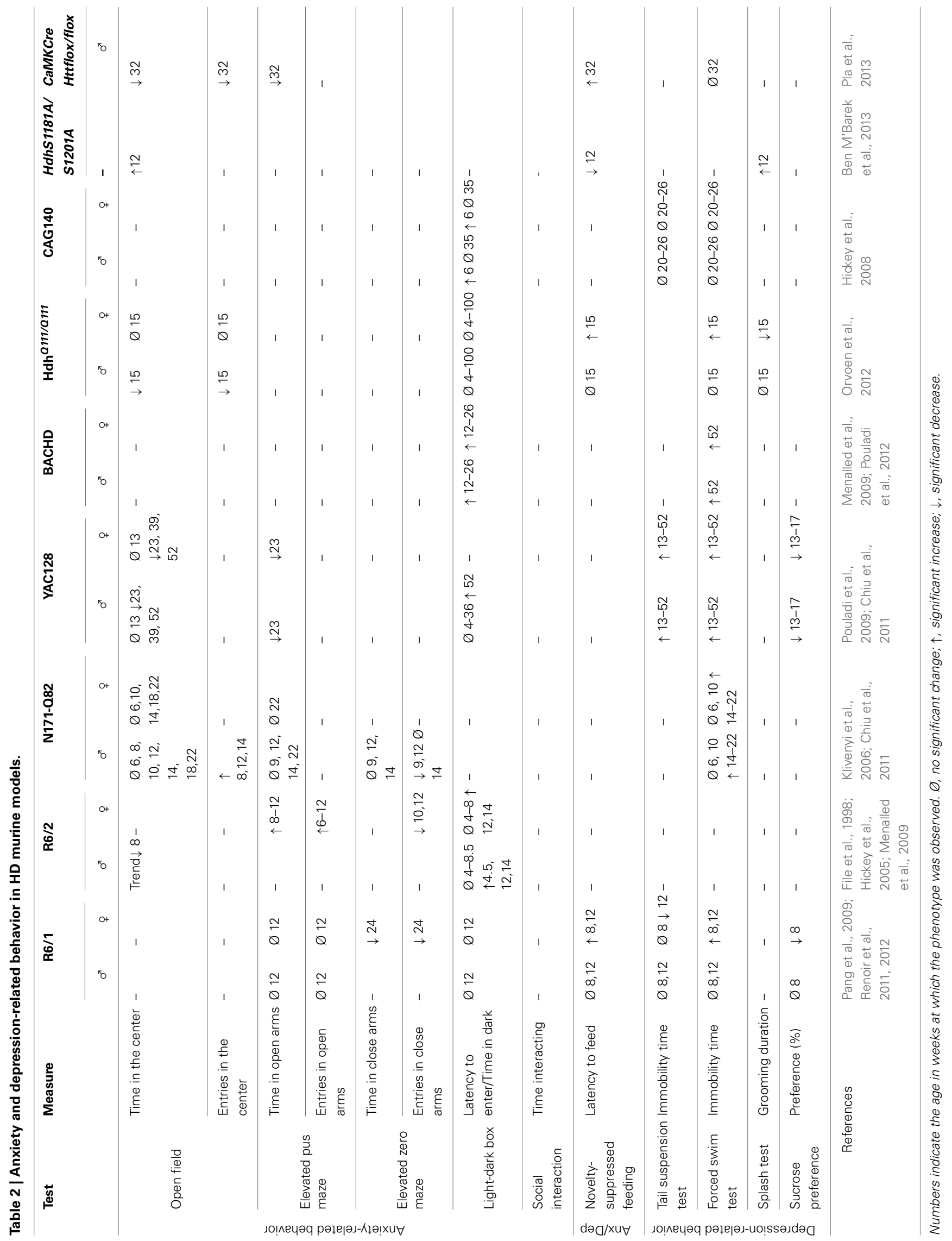


compared to wild-type mice, which represents a depressive-like behavior (Pouladi et al., 2009; Renoir et al., 2011). This behavior is sex-independent in YAC128 mice; however, the saccharinpreference of R6/1 female mice is lower than that of R6/1 male mice, or that of wild-type males or females.

In the splash test, low grooming frequency after a sucrose solution is squirted onto the mouse's fur can be interpreted as a loss of motivational behavior. This is thought to model some symptoms of depression, such as apathic behavior. Female, but not male $H d h^{Q 111 / Q 111}$ mice, show a depressive behavior in this test (Orvoen et al., 2012).

The forced swim test (FST) is widely used in pharmacology to screen for molecules with anti-depressant effects. It is also used to highlight a depressive-like behavior in rodents, linked to resignation, although the validity of this test as a measure of depression is debatable. Apart from CAG140, all of the HD models that were subjected to this test show a long duration of immobility, which indicates a depressive-like behavior in this paradigm (Grote et al., 2005; Hickey et al., 2008; Peng et al., 2008; Pouladi et al., 2009; Chiu et al., 2011; Renoir et al., 2011; Orvoen et al., 2012; Pouladi et al., 2012; Renoir et al., 2012). A long duration of immobility is associated with either a short swimming duration (YAC 128) (Pouladi et al., 2009), or a short climbing duration (Hdh ${ }^{\text {Q111/Q111 }}$ ) (Orvoen et al., 2012). According to Detke et al. (1995) and Page et al. (1999), short swimming duration indicates an alteration in serotonergic circuitry and short climbing duration indicates an alteration in noradrenergic circuitry. In the YAC128 mouse model the severity of depressive-like phenotypes tested with FST does not increase with age or with the progression of motor symptoms (Pouladi et al., 2009). Furthermore, the severity of the depressive-like phenotype is not correlated with the number of CAG repeats (Pouladi et al., 2009), similar to the situation in HD patients (Epping et al., 2013). There appears to be a sex-specific component of this depressive-like phenotype. Indeed, some studies report that mutated HTT is associated with a depressive-like phenotype in females but not in males, and in the R6/1 model, this phenotype manifests earlier in females than in males (Grote et al., 2005; Pang et al., 2009; Renoir et al., 2011; Orvoen et al., 2012). Thus, in the FST, the depressive-like phenotype has a sexspecific component, similar to findings for the sucrose-preference test.

The tail suspension test (TST) is another widely-used test in the screening for antidepressant drugs, and is also used to measure depressive-like behavior, linked to resignation, which is a function of the amount of time that the animal stays immobile. YAC128 mice show a high degree of immobility in the TST, which is consistent with findings of the FST (Chiu et al., 2011). However, the findings of the FST and TST involving R6/1 mice are inconsistent: in the TST, the duration of immobility is short for female R6/1 mice aged 12 weeks, suggesting that mutated HTT actually has an "antidepressant" effect (Pang et al., 2009). Nonetheless, another study found that the HD mutation does not affect TST performance of R6/1 mice at 8 weeks of age compared to wildtype mice (Renoir et al., 2011). The immobility duration of male or female CAG140 mice does not differ from that of wild-type mice in the TST, which is consistent with FST results in this strain (Hickey et al., 2008).
Altogether, results from different mouse strains using various behavioral tests show that HD mice exhibit anxiety- and depressive-like behavior. In various mouse models, a sex-specific component to these behaviors is evident: HD mutant females are more prone to depressive-like behaviors than mutant males (Pang et al., 2009; Orvoen et al., 2012), whereas mutant males are more prone to anxiety-like behaviors than mutant females (Hickey et al., 2005; Menalled et al., 2009; Orvoen et al., 2012). In humans, depression is roughly twice as prevalent in women as it is in men, and the reason of this difference is currently unknown (Kornstein et al., 2000).

\section{HTT, BDNF AND MOOD DISORDERS}

The general functions of HTT have been recently reviewed (Zuccato et al., 2010). Among other functions, wild-type HTT regulates the production, transport and release of BDNF, a function that is impaired when HTT is mutated or absent (see below). Microarray studies have shown that $B d n f^{+/-}$and forebrainspecific $B d n f^{-/-}$mice have transcription profiles similar to those of patients with HD or R6/2 mice (Strand et al., 2007), suggesting a major role for BDNF in the pathogenesis of HD. BDNF has been implicated in the physiopathology of mood disorders (Autry and Monteggia, 2012), and is thus the most obvious candidate linking HTT to mood disorders.

Wild-type HTT positively regulates Bdnf transcription (Cattaneo et al., 2005). Zuccato and colleagues showed that a neuron restrictive silencer element (NRSE) in the $B d n f$ promoter is indirectly targeted by wild-type HTT (Zuccato et al., 2003). Wildtype HTT inhibits the silencing activity of NRSE by sequestering its transcription factor (REST/NRSF) in the cytoplasm, leading to a high rate of $B d n f$ transcription. In contrast, in the context of HD, aberrant accumulation of REST/NRSF is observed in the nucleus, which impairs $B d n f$ transcription. Hence, one of the functions of HTT is to guarantee the sufficient production of BDNF via the sequestration of REST/NRSF. Mutated HTT also interferes with CREB function, which is an activator of $B d n f$ transcription (Zuccato et al., 2010). In agreement with these observations, low $B D N F$ expression has been observed in various brain regions of HD patients, including frontal cortex, striatum, hippocampus, substantia nigra, and cerebellum (Zuccato et al., 2001; Seo et al., 2004). In most mouse models of HD, the abundance of BDNF protein (Duan et al., 2003, 2008; Saydoff et al., 2006; Simmons et al., 2009; Xie et al., 2010) and Bdnf mRNA is decreased in mutant compared to normal mice in cortex, striatum and hippocampus (Zuccato et al., 2005; Pang et al., 2006; Zajac et al., 2010). It should be noted that striatal neurons express very low amount of BDNF mRNA (Altar et al., 1997). Therefore, the decrease of BDNF mRNA observed in striatum may not be biologically significant (as suggested in Pang et al., 2006). The diminished detection of BDNF at protein level in striatum may be attributed to a transport and secretion defect of neuronal BDNF coming from cortex or substantia nigra (see below). Studies have reported increased BDNF protein levels in anterior cortex or substantia nigra in R6/1 mice: this may be caused by an accumulation of BDNF linked to a transport deficit along corticostriatal or nigrostriatal pathways (Pineda et al., 2005; Pang et al., 2006) (see below). 
In addition to controlling the production of $B d n f$ mRNA, wild-type HTT regulates BDNF transport. Gauthier and colleagues found that BDNF transport in microtubules is stimulated by wild-type HTT (Gauthier et al., 2004). In contrast, cortical BDNF transport is impaired both in the presence of low amounts of wild-type HTT and by the expression of mutant HTT (Gauthier et al., 2004). Similar findings have also been demonstrated in hippocampal neurons (Pla et al., 2013). Defects in BDNF vesicular trafficking decrease the activitydependent release of BDNF from cortical and hippocampal neurons (Gauthier et al., 2004; Pla et al., 2013). This leads to the downregulation of the phosphorylation of AKT and Erk, both of which are regulated downstream of the interaction of BDNF with its receptor, TrkB (Pla et al., 2013).

HTT-mediated transport is microtubule-dependent and involves huntingtin-associated protein-1 (HAP1), which is implicated in axonal transport via its interaction with the microtubuledependent molecular motors kinesin and dynein, as well as the dynactin subunit p150 Glued (Li et al., 1998; McGuire et al., 2006; Rong et al., 2007). This complex is altered in the absence of HTT, or in the presence of mutated HTT containing an abnormally expanded polyQ tract. This alteration leads to the detachment of BDNF vesicles from microtubules (Gauthier et al., 2004; Zala et al., 2008).

Another argument in favor of the importance of HTT in axonal transport involves HTT phosphorylation. Indeed, HTT function is regulated by phosphorylation and the phosphorylation status of $\mathrm{HTT}$ affects BDNF transport and release. Phosphorylation of HTT at serine 421 by AKT and SGK specifically enhances the anterograde transport and release of BDNF at axon terminals (Humbert et al., 2002; Rangone et al., 2004; Colin et al., 2008). HTT is also phosphorylated at serines 1181 and 1201, which are both targets of Cdk5. In contrast to serine 421, dephosphorylation of these sites stimulates transport and release of BDNF (Ben M'Barek et al., 2013).

The density or the function of $\operatorname{TrkB}$, the receptor for BDNF, may also be altered due to defects in transcription and trafficking. Indeed, the transcriptional activity of $\operatorname{TrkB}$ is low in HD striatal neurons, independent of the production of BDNF (Ginés et al., 2010). Consistent with this finding, low amounts of $\operatorname{TrkB}$ are found in the caudate nucleus and/or cortex of HD post-mortem brains (Ginés et al., 2006; Zuccato et al., 2008). In addition to the transport of BDNF-containing vesicles, HTT also transports TrkB-containing vesicles. The retrograde transport of activated TrkB-containing endosomes is low in the presence of mutated HTT, leading to an impairment in neurotrophin signaling in striatal dendrites. This subsequently affects phospho-Erk and cfos within striatal neurons (Liot et al., 2013). An impairment in Ras/MAPK/ERK1/2 signaling resulting from a low abundance of TrkB may also be associated with the low abundance of p52/p46 Shc docking proteins in striatal cells expressing polyQ-HTT (Ginés et al., 2010). Rab11 is also important for TrkB distribution in dendrites (Lazo et al., 2013) and defects of Rab11 recycling endosomes have been observed in HD (Li et al., 2010).

Therefore, by dysregulating transcription, trafficking and signaling at multiple levels, mutant HTT impairs both the ligand and the receptor in the BDNF/TrkB pathway (Figure 1).

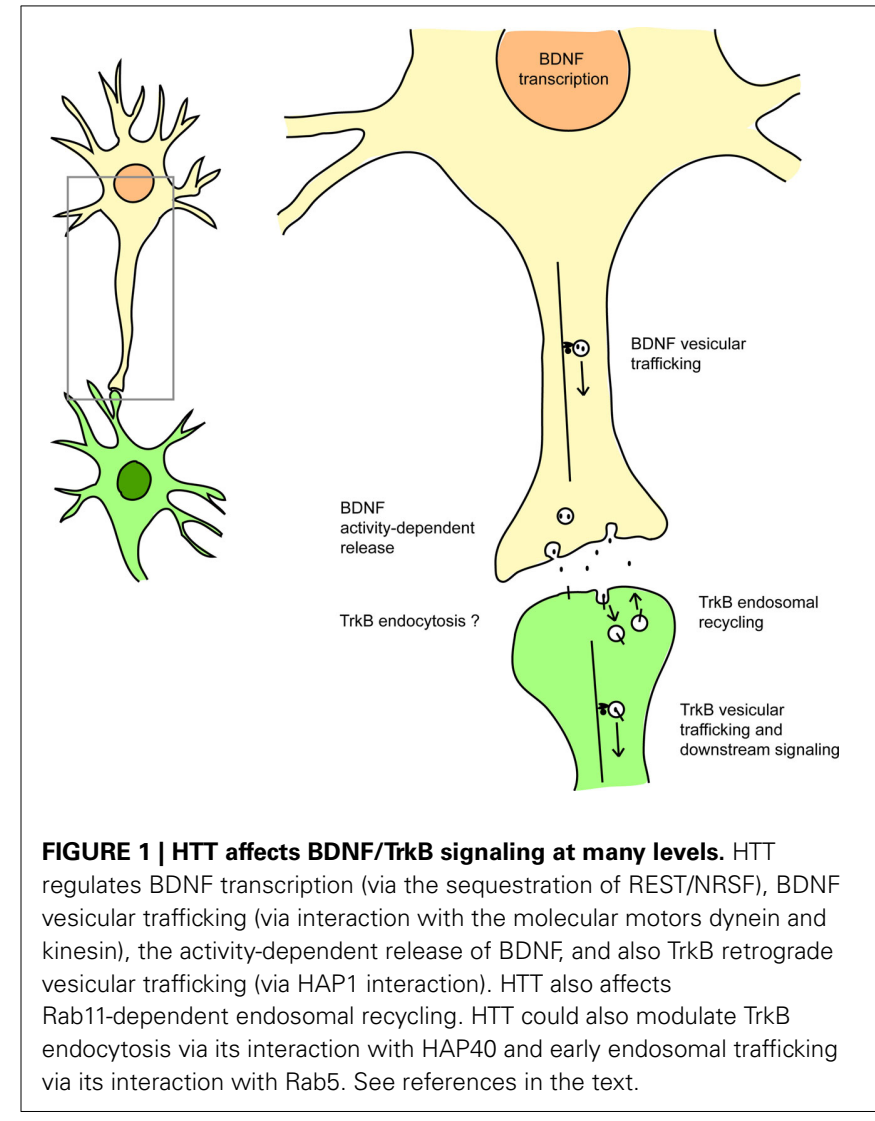

However, the hypothesis that the impairment of the $\mathrm{BDNF} / \mathrm{TrkB}$ pathway alone can lead to mood disorder is still a matter of debate. Most studies support the conclusion that an impairment in the production of BDNF is not associated with profound changes to depression-related behavior (Autry and Monteggia, 2012). Yet, in the forced swim test and in the sucrose preference test, female mice lacking BDNF show a high degree of depressive-like behavior (Monteggia et al., 2007). This is similar to the situation in $\mathrm{HD}$, in which females are more prone to depressive-like behaviors than males. In R6/1 mice, the production of BDNF is mostly affected in females, because the abundance of a large number of $B d n f$ isoforms (BDNF I, II, III, IV and VI) is low in females, whereas in males only BDNF I and VI transcripts are affected (Zajac et al., 2010).

In contrast, there is a clear link between anxiety-related behavior and BDNF signaling. KI mice that express BDNF containing a point mutation (valine 66 to methionine substitution, Val/Met 66) that mimics a mutation found in human populations, show impairment in BDNF secretion and exhibit high levels of anxietylike behavior in open field and elevated plus maze tests (Chen et al., 2006). Genetic or pharmacological inhibition of TrkB also results in the modification of anxiety-related behavior (Bergami et al., 2008; Cazorla et al., 2010). Conversely, antidepressants such as SSRIs, tricyclic molecules, or monoamine oxidase-A inhibitors are able to rapidly activate BDNF/TrkB signaling (Saarelainen et al., 2003; Rantamäki et al., 2007). 
New discoveries have highlighted a role for BDNF production and HTT in cell types other than neurons. BDNF produced by astrocytes can modify mood-related behavior in mice (Quesseveur et al., 2013). Expression of a mutated fragment of HTT in astrocytes causes age-dependent neurological symptoms, including motor function deficits (Bradford et al., 2009). Anxiety or depressive-related behaviors were not examined in these mice and such a study would be of interest.

Finally, many studies demonstrate that the efficacy of antidepressant treatments depends on fully functioning BDNF production and signaling (Monteggia et al., 2004; Malberg and Blendy, 2005; Monteggia et al., 2007; Hu and Russek, 2008; Li et al., 2008). Thus, restoration of the "normal" levels of BDNF could be a therapy for HD patients. Normal levels of BDNF can be restored by physical exercise in HD models. According to Zajac et al. (2010), the abundance of total Bdnf mRNA that is low in the hippocampus of both male and female $\mathrm{R} 6 / 1$ mice is significantly increased by wheel-running activity in female R6/1 mice and wild-type mice (but not in male R6/1 mice). Environmental enrichment is another method that promotes BDNF production. Environmental enrichment is associated with a high abundance of $B d n f$ mRNA in the hippocampus of male wild-type animals (Zajac et al., 2010) and environmental stimulation benefits patients with HD (Sullivan et al., 2001).

\section{HTT AND HIPPOCAMPAL ADULT NEUROGENESIS}

The amount of neurogenesis in the hippocampal dentate gyrus (DG) is associated with anxiety state. Intriguingly, both high or low levels of DG neurogenesis have been associated with anxiogenic behavior, suggesting that an optimal level of DG neurogenesis is important to maintain a normal anxiety-related state (Fuss et al., 2010). Low levels of neurogenesis alone are not sufficient to trigger a depression-like phenotype; however, neurogenesis is necessary for some of the beneficial effects of anti-depressant treatments (Samuels and Hen, 2011; Mendez-David et al., 2014).

Neurogenesis in the subventricular zone (SVZ) is increased in post-mortem HD brain tissue (Curtis et al., 2003). However, neurogenesis in the DG has not been examined in HD patients. In HD rodent models, adult neurogenesis is altered in the hippocampus whereas no significant alteration of neurogenesis in the SVZ has been observed (Gil et al., 2005; Phillips et al., 2005; Lazic et al., 2006;). This suggests that the mechanism with which HTT controls neurogenesis is region-specific. The discrepancy between patients and mice regarding neurogenesis in the SVZ could be explained by the fact that the loss of striatal neurons is more detrimental for humans than for mice; thus, a compensatory activation of neurogenesis in the SVZ could be triggered in humans but not in mice (Curtis et al., 2003).

HD mouse models show defects in cellular proliferation in the DG, however these defects occur during the late stages of disease progression. In the DG of R6/1 mice, cell proliferation is low only when mice already exhibit motor deficits (Lazic et al., 2004, 2006; Walker et al., 2011). Similarly, YAC 128 mice show normal cell proliferation in the DG prior to the onset of motor deficits. However, these mice have $26 \%$ fewer proliferating cells in the DG when they are 18 months old compared to wild-type mice (Simpson et al., 2011). No defect in cellular proliferation is observed for $H d h^{Q 111 / Q 111}$ mice before the onset of motor deficits, and similarly, cellular proliferation in the loss of function CaMKCreER ${ }^{T 2}$; $\mathrm{Ht}^{\text {flox/flox }}$ mice is not affected (Orvoen et al., 2012; Pla et al., 2013).

In contrast to proliferation, the differentiation and survival of new-born DG neurons are affected during the early stages of disease progression, before the onset of motor deficits. YAC128 mice show morphological alterations to DG immature neurons (Simpson et al., 2011). Male but not female $H d h^{Q 111 / Q 111}$ mice have defects of dendritic arborization of newborn DG neurons (Orvoen et al., 2012). This correlates well with anxiety-related behavior because only male $H d h^{Q 111 / Q 111}$ mice show anxiety-like behavior (Orvoen et al., 2012). This correlation extends to the loss-of-function $\mathrm{CaMKCreER}^{T 2}$; $H t t^{\text {flox/flox }}$ model, in which anxiety-like behavior is also associated with defects of dendritic arborization and the poor longterm survival of new-born DG neurons (Pla et al., 2013). Conversely, in KI mice that express HTT containing nonphosphorylatable serines 1181 and 1201, an anxiolytic-like behavior is associated with an increase of dendritic arborization and survival of newborn DG neurons (Ben M'Barek et al., 2013).

The deletion of $\mathrm{Htt}$ in mature cortical and hippocampal neurons affects only anxiety-related behavior and not depressiverelated behavior (Pla et al., 2013). Female $H d h^{Q 111 / Q 111}$ mice have a depressive-like phenotype without perturbation of neurogenesis (Orvoen et al., 2012). Hence in HD, depression could be related to defects in other neuronal systems, such as raphe serotonergic neurons (see below).

The origin of defects of hippocampal neurogenesis may be non-cell autonomous, as is the case for CaMKCreER ${ }^{T 2} ; \mathrm{Ht}^{\text {flox } / \text { flox }}$ mice. In these mice, HTT is specifically depleted in adult mature cortical and hippocampal neurons. However, new-born neurons show defects in dendritogenesis and survival, despite the fact that $\mathrm{Htt}$ is still expressed in these neurons (Pla et al., 2013). The phenotype of these new-born neurons is similar to that of TrkBdepleted new-born neurons (Bergami et al., 2008). This suggests that BDNF may be involved in the non-cell autonomous effect of mature neurons on new-born neurons.

Natural or induced changes to the abundance of BDNF have been associated with changes to adult hippocampal neurogenesis in several studies (Lee et al., 2002; Duman, 2004; Sairanen et al., 2005). However, although physical exercise promotes the production of BDNF, this is not associated with an improvement to hippocampal neurogenesis in various HD models (Kohl et al., 2007; Renoir et al., 2012). Thus, in the context of HD, the production of BDNF does not seem to restore normal hippocampal neurogenesis. The exercise-dependent stimulation of neurogenesis depends on PI3K-Akt signaling (Bruel-Jungerman et al., 2009), which acts downstream of $\mathrm{BDNF} / \mathrm{TrkB}$. Hence, the absence of a proneurogenic response to exercise in these HD models could be linked to the aforementioned defects of BDNF/TrkB signaling. Other players may also be involved, such as the serotonergic system. 


\section{HTT AND THE SEROTONERGIC SIGNALING}

Dysregulation of the raphe serotonergic system has been implicated as an important factor in mood disorders, including depression (Donaldson et al., 2013). Similarly, several observations point to a dysregulation of this system in HD. A study using transcranial ultrasound found a correlation between raphe echogenicity and the level of depression in patients with HD (Krogias et al., 2011). Concentrations of 5-hydroxytryptamine (5-HT) and its metabolite 5-hydroxyindolacetic acid (5-HIAA), which are often low in patients with major depression, are also low in HD patients (Caraceni et al., 1977; Jongen et al., 1980), whereas the activity of monoamine oxydase A enzyme activity (which catalyzes the breakdown of 5-HT) is high (Richards et al., 2011). Furthermore, 5-HT binding to its receptor is also impaired, as assessed in postmortem HD brains (Waeber and Palacios, 1989; Steward et al., 1993; Wong et al., 1996). The Htr1A and Htr1B receptor subtypes appear to be particularly affected (Castro et al., 1998; Yohrling et al., 2002). The expression of serotonergic receptors is perturbed in murine HD models (Pang et al., 2009; Renoir et al., 2012). The expression of Htrla, Htrlb, and Htr $2 a$ is low, whereas the expression of $\mathrm{Htr} 2 \mathrm{c}$ is normal. Lower concentrations of serotonin (and also of 5-HIAA), dopamine, and noradrenaline were found in the striatum, cortex, and hippocampus of R6/1 mice compared to wild-type mice (Renoir et al., 2011).

The behavior of R6/1 mice, including its sex-specific component, resembles that of $\mathrm{Htr} 1 \mathrm{a}^{-/-}$, or $\mathrm{Htr}_{\mathrm{l}} \mathrm{b}^{-/-}$, or SERT $\mathrm{T}^{-/-}$mice (Gross et al., 2000; Mayorga et al., 2001; Holmes et al., 2002; Lira et al., 2003; Jones and Lucki, 2005). Gene expression studies have found changes to the expression of Htrla, Htrbl, and SERT in the brains of R6/1 mice (Pang et al., 2009), suggesting that alterations of mood behavior in HD mice could be caused, at least in part, by a low abundance of these 5-HT receptors and this 5-HT transporter. The expression of Htrlb is lower in R6/1 females than in males (Pang et al., 2009), making Htrlb an obvious candidate to explain sex-specific differences in mood behavior. Female R6/1 mice are more sensitive than males to the Htrla receptor agonist 8-OH DPAT in the 8-OH DPAT-induced hypothermia test, suggesting sex-specific Htr1a hypersensitivity (Renoir et al., 2011, 2012). SSRI sertraline treatment in female R6/1 mice was associated with both a reduction in depressive-like behavior and in the hypersensitivity of Htrla autoreceptors (Renoir et al., 2012). This is consistent with observations in humans because sertraline is more effective for the treatment of chronic depression in women than in men (Kornstein et al., 2000).

It is not known if mutant HTT directly affects the transcription of genes encoding serotonergic receptors or transporters. However, serotonergic signaling may affect the expression of HTT. Indeed, in Htrla/Htrlb double $\mathrm{KO}$ mice, which have a hyperserotonergic phenotype and show anxiety-related behavior, the expression of $\mathrm{Htt}$ and other HD-related genes is perturbed (Xia et al., 2012).

Serotonergic signaling can affect hippocampal neurogenesis. This effect depends on the serotonin receptor involved, although the overall effect is pro-neurogenic (Klempin et al., 2010). Therefore, the low abundance of various serotonin receptors that is observed in the hippocampus in HD models (see above) could at least partially explain the defects in DG neurogenesis.
TrkB is expressed on serotonergic raphe neurons and BDNF produced in the hippocampus can be retrogradely transported to the raphe (Anderson et al., 1995; Madhav et al., 2001). BDNF/TrkB signaling affects the function of serotonergic neurons. For example, $B d n f^{+/-}$mice show changes in serotonergic innervations of the cortex, hypothalamus, and hippocampus (Lyons et al., 1999; Luellen et al., 2007) and it would be interesting to examine the densities of serotonergic innervations in HD models.

\section{HTT AND THE HPA AXIS}

The hypothalamic-pituitary-adrenal axis (HPA) is the main regulator of the stress response. In the HPA axis, cortisol secretion is controlled by the hypothalamic corticotrophin releasing hormone $(\mathrm{CRH})$ and pituitary adrenocorticotropic hormone (ACTH). Stress leads to the hyper-secretion of corticosteroids by the adrenal glands and this is associated with a high risk of anxiety and depression. Therefore, changes to the activity of the HPA axis are common in patients with depression (Antonijevic, 2006). Chronic treatment of rodents with corticosterone induces anxiety- and depression-related behavior (Ardayfio and Kim, 2006; Gourley et al., 2008; Murray et al., 2008; David et al., 2009). The acute or chronic administration of corticosterone in mice is associated with impairment of neurogenesis and poor neuronal survival in the hippocampus (Cameron and Gould, 1994; Karishma and Herbert, 2002; Murray et al., 2008; David et al., 2009).

HPA hyperactivity has been observed in HD patients (Heuser et al., 1991; Leblhuber et al., 1995; Björkqvist et al., 2006; Aziz et al., 2009). In saliva samples taken early in the morning, presymptomatic HD carriers show higher cortisol concentrations than controls (Van Duijn et al., 2010). During the early stages of $\mathrm{HD}$, salivary concentrations of cortisol in the morning are higher in depressed patients than in non-depressed patients (Shirbin et al., 2013). High concentrations of cortisol have been measured in transgenic R6/2 mice (Björkqvist et al., 2006) but also specifically in female R6/1 mice subjected to physiological or pharmacological stresses (Du et al., 2012). This may explain the tendency of HD female mice to have more depressive-like phenotypes than HD male mice in various models. Furthermore, testosterone has a protective effect against HPA hyperactivity (Rubinow et al., 2005).

\section{CONCLUSIONS AND PERSPECTIVES}

Studies of anxiety and depression have mainly focused on the hippocampus, serotonergic signaling, and to a lesser extent, the HPA axis (Figure 2). However, depression involves perturbations of many other regions such as the prefrontal cortex, the cingulate cortex, the striatum, the amygdala, and the thalamus (Nestler et al., 2002). In the context of HD, research has historically concentrated on perturbations to the striatum with a focus on motor control. However, striatal alterations have also been implicated in HD early cognitive defects like executive dysfunction (Peinemann et al., 2005) and future studies may also implicate striatal dysfunction in mood disorders in HD patients. All these regions are highly interconnected and mood disorders alter these circuits. It seems reasonable to think that depression and anxiety that are associated with HD have several origins within these circuits. 


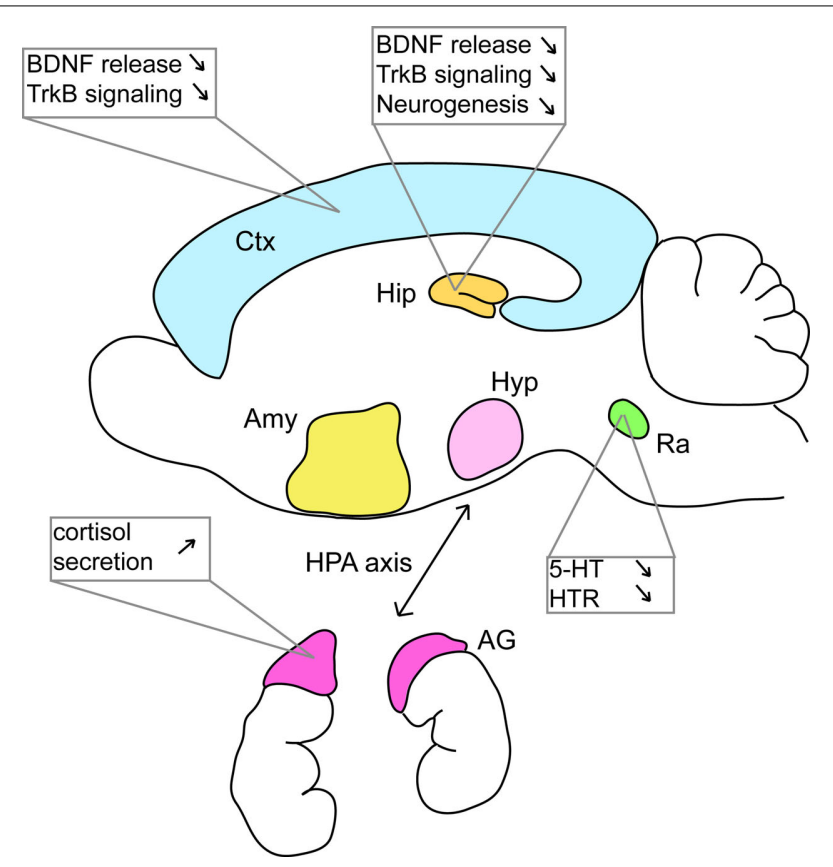

FIGURE 2 | Many defects at various locations in the brain of HD murine models can be linked to mood disorders. Studies in mouse models of $\mathrm{HD}$ have shown that BDNF/TrkB signaling is altered in various brain regions. Alterations of the serotonergic system and of the HPA axis have also been documented. AG, adrenal gland; Amy, amygdala; Ctx, cortex; Hip,

hippocampus; Hyp, hypothalamus; Ra, raphe nuclei. See references in the text.

Targeted deletion or KI mouse models could be used to answer this question. Recently, Du et al. (2013) proposed that dysfunction of the HPA axis could trigger a cascade of events participating to mood disorders in patients with HD.

Defects in adult hippocampal neurogenesis have also been implicated in cognitive alteration of learning and memory, which are also present in HD. Therefore, the study of hippocampal neurogenesis will benefit not only our understanding of mood alterations in patients with $\mathrm{HD}$, but also our understanding of cognitive deficits in these patients. In addition, BDNF has been implicated in hippocampal neurogenesis but is also involved in the development and maintenance of dendritic spines (Tyler and Pozzo-Miller, 2003; Alonso et al., 2004; Von Bohlen und Halbach et al., 2006, 2008), as well as synaptic plasticity (Gomez-PalacioSchjetnan and Escobar, 2013). Thus, defects of BDNF/TrkB signaling that are described for HD models may also affect cognition. In this regard, it is interesting to note that depression is also associated with poor cognitive performance in patients with $\mathrm{HD}$ (Smith et al., 2012).

HTT controls the intracellular trafficking of other ligands and receptors besides BDNF and TrkB. Perturbation of this trafficking in the presence of mutated HTT may also contribute to the pathology of mood disorders For example, polyQHTT alters $\mathrm{GABA}_{\mathrm{A}} \mathrm{R}$ vesicle trafficking, resulting in the loss of $\mathrm{GABA}_{\mathrm{A}} \mathrm{R}$ surface delivery and in a low inhibitory synaptic response (Twelvetrees et al., 2010; Yuen et al., 2012). GABA $\mathrm{R}$ dysfunction is implicated in mood disorders (Rudolph and Möhler, 2014). GABA interneurons are inhibited by 5-HT1A receptors in basolateral amygdala, an area implicated in anxiety and fear processing (Rainnie, 1999). Moreover, NMDA receptor signaling pathways are perturbed in HD patients (Young et al., 1988). In transgenic YAC models of HD, alteration of NMDA receptor activity that affects long-term potentiation (LTP) is an early event prior to any motor or cognitive defects (Hodgson et al., 1999; Milnerwood and Raymond, 2007).

Another level of complexity that remains to be explored is the role of the various fragments of HTT that are generated during the progression of HD. Mutated HTT is cleaved by caspases. In particular, caspase- 6 cleavage represents an important event mediating neuronal dysfunction and neurodegeneration (Gafni et al., 2004; Graham et al., 2006). YAC mice expressing a caspase6-resistant mutant HTT exhibit only a moderate impairment of motor functions but also a modest depressive-like phenotype (Pouladi et al., 2009). These data suggest that caspase-6-mediated cleavage of HTT is an important trigger of depressive behavior. As some N-terminal fragments do not recapitulate full-length HTT functions, proteolysis event could be linked to the inactivation of HTT protein function.

BDNF release and signaling is decreased in the hippocampus in the context of $\mathrm{HD}$, which is probably associated with the loss of HTT function in vesicular transport. However, BDNF signaling is increased in the amygdala and in the nucleus accumbens during major depression or stress disorders (Berton et al., 2006; Krishnan et al., 2007; Yu and Chen, 2011). Whether this is also true for depressed or stressed patients with HD and HD mouse models remains to be explored. If the activity of BDNF signaling is high in the amygdala and in the nucleus accumbens in the context of HD, then this would suggest that mutated HTT has region-specific effects on BDNF signaling. Little is known about the functions of HTT in the "fear" and in the reward systems where amygdala and nucleus accumbens are implicated respectively.

The underlying unresolved question is as follows: are the depressive symptoms observed for patients with HD different from those of individuals without HD? In other words, are the mechanisms at the basis of depression in patients with HD specific to this disease? The loss of HTT specifically in mature hippocampal neurons affects anxio-depressive behavior and the phosphorylation of HTT at S1181/1201 also appears to regulate mood-related behavior in mouse models of HD. These observations suggest that HTT is part of the physiological cascade controlling anxio-depressive behavior. Hence, the interest of studying HTT extends beyond HD. HTT could constitute a novel target for therapy in anxiety and depression both in patients with $\mathrm{HD}$ and in the general population. This could be important given that the effectiveness of currently available drugs is highly variable for many patients (Samuels and Hen, 2011; Kupfer et al., 2012).

\section{ACKNOWLEDGMENTS}

We greatly acknowledge Fabienne Agasse for her critical reading of the manuscript. The Humbert and Saudou laboratories (Patrick Pla, Frédéric Saudou, Sandrine Humbert) are funded by grants from Agence Nationale pour la Recherche (ANR), 
Association pour la Recherche sur le Cancer (ARC), Fondation pour la Recherche Médicale (FRM). Denis J. David is a recipient of the Young Investigator Award from The Brain \& Behavior Research Foundation and he is currently receiving investigatorinitiated research support from Lundbeck, Roche, and Servier.

\section{REFERENCES}

Almqvist, E. W., Brinkman, R. R., Wiggins, S., Hayden, M. R., and The Canadian Collaborative Study of Predictive Testing. (2003). Psychological consequences and predictors of adverse events in the first 5 years after predictive testing of HD. Clin. Genet. 64, 300-309. doi: 10.1034/j.1399-0004.2003.00157.x

Alonso, M., Medina, J. H., and Pozzo-Miller, L. (2004). ERK1/2 activation is necessary for BDNF to increase dendritic spine density in hippocampal CA1 pyramidal neurons. Learn. Mem. 11, 172-178. doi: 10.1101/lm.67804

Altar, C. A., Cai, N., Bliven, T., Juhasz, M., Conner, J. M., Acheson, A. L., et al. (1997). Anterograde transport of brain-derived neurotrophic factor and its role in the brain. Nature 389, 856-860. doi: 10.1038/39885

Anderson, K. D., Alderson, R. F., Altar, C. A., DiStefano, P. S., Corcoran, T. L., Lindsay, R. M. and Wiegand, S. J. (1995). Differential distribution of exogenous BDNF, NGF and NT- 3 in the brain corresponds to the relative abundance and distribution of high-affinity neurotrophin receptors. J. Comp. Neurol. 357, 296-317.

Antonijevic, I. A. (2006). Depressive disorders: is it time to endorse different pathophysiologies? Psychoneuroendocrinology $31,1-15 . \quad$ doi: 10.1016/j.psyneuen.2005.04.004

Ardayfio, P., and Kim, K.-S. (2006). Anxiogenic-like effect of chronic corticosterone in the light-dark emergence task in mice. Behav. Neurosci. 120, 249-256. doi: 10.1037/0735-7044.120.2.249

Autry, A. E., and Monteggia, L. M. (2012). Brain-derived neurotrophic factor and neuropsychiatric disorders. Pharmacol. Rev. 64, 238-258. doi: 10.1124/pr.111.005108

Aziz, N. A., Pijl, H., Frölich, M., van der Graaf, A. W., Roelfsema F., and Roos, R. A. (2009). Increased hypothalamic-pituitary-adrenal axis activity in Huntington's disease. J. Clin. Endocrinol. Metab. 94, 1223-1228. doi: 10.1210/jc.2008-2543

Ben M'Barek, K., Pla, P., Orvoen, S., Benstaali, C., Godin, J. D., Gardier, A. M., et al. (2013). Huntingtin mediates anxiety/depression-related behaviors and hippocampal neurogenesis. J. Neurosci. 33, 8608-8620. doi: 10.1523/J.NEUROSCI.5110-12.2013

Bergami, M., Rimondini, R., Santi, S., Blum, R., Götz, M., and Canossa, M. (2008). Deletion of TrkB in adult progenitors alters newborn neuron integration into hippocampal circuits and increases anxiety-like behavior. Proc. Natl. Acad. Sci. U.S.A. 105, 15570-15575. doi: 10.1073/pnas.0803702105

Berrios, G. E., Wagle, A. C., Markova, I. S., Wagle, S. A., Ho, L. W., Rubinsztein, D. C., et al. (2001). Psychiatric symptoms and CAG repeats in neurologically asymptomatic Huntington's disease gene carriers. Psychiatry Res. 102, 217-225. doi: 10.1016/S0165-1781(01)00257-8

Berton, O., McClung, C. A., Dileone, R. J., Krishnan, V., Renthal, W., Russo, S. J., et al. (2006). Essential role of BDNF in the mesolimbic dopamine pathway in social defeat stress. Science 311, 864-868. doi: 10.1126/science.1120972

Björkqvist, M., Petersén, A., Bacos, K., Isaacs, J., Norlén, P., Gil, J., et al. (2006). Progressive alterations in the hypothalamic-pituitary-adrenal axis in the R6/2 transgenic mouse model of Huntington's disease. Hum. Mol. Genet. 15, 1713-1721. doi: 10.1093/hmg/ddl094

Bradford, J., Shin, J.-Y., Roberts, M., Wang, C.-E., Li, X.-J., and Li, S. (2009). Expression of mutant huntingtin in mouse brain astrocytes causes age-dependent neurological symptoms. Proc. Natl. Acad. Sci. U.S.A. 106, 22480-22485. doi: 10.1073/pnas.0911503106

Bruel-Jungerman, E., Veyrac, A., Dufour, F., Horwood, J., Laroche, S., and Davis, S. (2009). Inhibition of PI3K-Akt signaling blocks exercise-mediated enhancement of adult neurogenesis and synaptic plasticity in the dentate gyrus. PLoS ONE 4:e7901. doi: 10.1371/journal.pone.0007901

Cameron, H. A., and Gould, E. (1994). Adult neurogenesis is regulated by adrenal steroids in the dentate gyrus. Neurosci. 61, 203-209.

Caraceni, T., Calderini, G., Consolazione, A., Riva, E., Algeri, S., Girotti, F., et al. (1977). Biochemical aspects of Huntington's chorea. J. Neurol. Neurosurg. Psychiatry 40, 581-587. doi: 10.1136/jnnp.40.6.581

Castro, M. E., Pascual, J., Romon, T., and Pazos, A. (1998). 5-HT 1B receptor binding in degenerative movement disorders. Brain Res. 790, 323-328.
Cattaneo, E., Zuccato, C., and Tartari, M. (2005). Normal huntingtin function: an alternative approach to Huntington's disease. Nat. Rev. Neurosci. 6, 919-930. doi: $10.1038 / \mathrm{nrn} 1806$

Cazorla, M., Jouvenceau, A., Rose, C., Guilloux, J.-P., Pilon, C., Dranovsky, A., et al. (2010). Cyclotraxin-B, the first highly potent and selective TrkB inhibitor, has anxiolytic properties in mice. PLoS ONE 5:e9777. doi: 10.1371/journal.pone.0009777

Chari, A., Quiraishi, S. H., and Jainer, A. K. (2003). Fluoxetine-induced exacerbation of chorea in Huntington's disease ? A case report. Pharmacopsychiatry 36, 41-43. doi: 10.1055/s-2003-38093

Chen, Z. Y., Jing, D., Bath, K. G., Ieraci, A., Khan, T., Siao, C. J., et al. (2006). Genetic variant BDNF (Val66Met) polymorphism alters anxiety-related behavior. Science 314, 140-143. doi: 10.1126/science.1129663

Chiu, C.-T., Liu, G., Leeds, P., and Chuang, D.-M. (2011). Combined treatment with the mood stabilizers lithium and valproate produces multiple beneficial effects in transgenic mouse models of Huntington's disease. Neuropsychopharmacology 36, 2406-2421. doi: 10.1038/npp.2011.128

Ciamei, A., and Morton, A. J. (2008). Rigidity in social and emotional memory in the R6/2 mouse model of Huntington's disease. Neurobiol. Learn. Mem. 89, 533-544. doi: 10.1016/j.nlm.2007.10.009

Colin, E., Zala, D., Liot, G., Rangone, H., Borrell-Pagès, M., Li, X.-J., et al. (2008). Huntingtin phosphorylation acts as a molecular switch for anterograde/retrograde transport in neurons. EMBO J. 27, 2124-2134. doi: 10.1038/emboj.2008.133

Craufurd, D., Thompson, J. C., and Snowden, J. S. (2001). Behavioral change in Huntington disease. Neuropsychiatry Neuropsychol. Behav. Neurol. 14, 219-226.

Curtis, M. A., Penney, E. B., Pearson, A. G., van Roon-Mom, W. M. C., Butterworth, N. J., Dragunow, M., et al. (2003). Increased cell proliferation and neurogenesis in the adult human Huntington's disease brain. Proc. Natl. Acad. Sci. U.S.A. 100, 9023-9027. doi: 10.1073/pnas.1532244100

David, D. J., Samuels, B. A., Rainer, Q., Wang, J., Marsteller, D., Mendez, I. et al. (2009). Neurogenesis-dependent and -independent effects of fluoxetine in an animal model of anxiety/depression. Neuron 62, 479-493. doi: 10.1016/j.neuron.2009.04.017

Detke, M. J., Rickels, M., and Lucki, I. (1995). Active behaviors in the rat forced swimming test differentially produced by serotonergic and noradrenergic antidepressants. Psychopharmacology 121, 66-72

Dietrich, P., Shanmugasundaram, R., Shuyu, E., and Dragatsis, I. (2009). Congenital hydrocephalus associated with abnormal subcommissural organ in mice lacking huntingtin in Wntl cell lineages. Hum. Mol. Genet. 18, 142-150. doi: $10.1093 / \mathrm{hmg} / \mathrm{ddn} 324$

Donaldson, Z. R., Nautiyal, K. M., Ahmari, S. E., and Hen, R. (2013). Genetic approaches for understanding the role of serotonin receptors in mood and behavior. Curr. Opin. Neurobiol. 23, 399-406. doi: 10.1016/j.conb.2013. 01.011

Dragatsis, I., Levine, M. S., and Zeitlin, S. (2000). Inactivation of Hdh in the brain and testis results in progressive neurodegeneration and sterility in mice. Nat. Genet. 26, 300-306. doi: 10.1038/81593

Du, X., Leang, L., Mustafa, T., Renoir, T., Pang, T. Y., and Hannan, A. J. (2012). Environemental enrichement rescues female-specific hyperactivity of the hypothalamic-pituitary-adrenal axis in a model of Huntington's disease. Transl. Psychiatry 2:e133. doi: 10.1038/tp.2012.58

Du, X., Pang, T. Y., and Hannan, A. J. (2013). A tale of two maladies? Pathogenesis of depression with and without the Huntington's Disease Gene Mutation. Front. Neurol. 4:81. doi: 10.3389/fneur.2013.00081

Duan, W., Guo, Z., Jiang, H., Ware, M., Li, X.-J., and Mattson, M. P. (2003). Dietary restriction normalizes glucose metabolism and BDNF levels, slows disease progression, and increases survival in huntingtin mutant mice. Proc. Natl. Acad. Sci. U.S.A. 100, 2911-2916. doi: 10.1073/pnas.0536856100

Duan, W., Peng, Q., Masuda, N., Ford, E., Tryggestad, E., Ladenheim, B., et al. (2008). Sertraline slows disease progression and increases neurogenesis in N171-82Q mouse model of Huntington's disease. Neurobiol. Dis. 30, 312-322. doi: 10.1016/j.nbd.2008.01.015

Duff, K., Paulsen, J. S., Beglinger, L. J., Langbehn, D. R., and Stout, J. C. (2007). Psychiatric symptoms in Huntington's disease before diagnosis?: the predict-HD study. Biol. Psychiatry 62, 1341-1346. doi: 10.1016/j.biopsych.2006. 11.034

Duman, R. S. (2004). Role of neurotrophic factors in the etiology and treatment of mood disorders. Neuromolecular Med. 5, 11-25. doi: 10.1385/NMM:5:1:011 
Duyao, M. P., Auerbach, A. B., Ryan, A., Persichetti, F., Barnes, G. T., McNeil, S. M., et al. (1995). Inactivation of the Mouse Huntington's disease gene homolog Hdh. Science 269, 6182-6195.

Epping, E. A., Mills, J. A., Beglinger, L. J., Fiedorowicz, J. G., Craufurd, D., Smith, M. M., et al. (2013). Characterization of depression in prodromal Huntington disease in the neurobiological predictors of HD (PREDICT-HD) study. J. Psychiatr. Res. 47, 1423-1431. doi: 10.1016/j.jpsychires.2013.05.026

Epping, E. A., and Paulsen, J. S. (2011). Depression in the early stages of Huntington disease. Neurodegener. Dis. Manag. 1, 407-414. doi: 10.2217/nmt.11.45

File, S. E., Mahal, A., Mangiarini, L., and Bates, G. P. (1998). Striking changes in anxiety in Huntington's disease transgenic mice. Brain Res. 805, 234-240. doi: 10.1016/S0006-8993(98)00736-7

Folstein, S. E., Chase, G. A., Wahl, W. E., McDonnell, A. M., and Folstein, M. F. (1987). HD in Maryland?: clinical aspects of racial variation. Am. J. Hum. Genet. $41,168-179$.

Frank, S. (2010). Tetrabenazine: the first approved drug for the treatment of chorea in US patients with Huntington's disease. Neuropsychiatr. Dis. Treat. 6, 657-665. doi: 10.2147/NDT.S6430

Fuss, J., Ben Abdallah, N. M. B., Hensley, F. W., Weber, K.-J., Hellweg, R., and Gass, P. (2010). Deletion of running-induced hippocampal neurogenesis by irradiation prevents development of an anxious phenotype in mice. PLoS ONE 5:e12769. doi: 10.1371/journal.pone.0012769

Gafni, J., Hermel, E., Young, J. E., Wellington, C. L., Hayden, M. R., and Ellerby, L. M. (2004). Inhibition of calpain cleavage of huntingtin reduces toxicity: accumulation of calpain/caspase fragments in the nucleus. J. Biol. Chem. 279, 20211-20220. doi: 10.1074/jbc.M401267200

Gauthier, L. R., Charrin, C., Dompierre, J. P., Borrell-Pagès, M., Cordelières, F. P., De Mey, J., et al. (2004). Huntingtin controls neurotrophic support and survival of neurons by enhancing BDNF vesicular transport along microtubules. Cell 118, 127-138. doi: 10.1016/j.cell.2004.06.018

Gil, J. M. A. C., Mohapel, P., Araújo, I. M., Popovic, N., Li, J.-Y., Brundin, P., et al. (2005). Reduced hippocampal neurogenesis in R6/2 transgenic Huntington's disease mice. Neurobiol. Dis. 20, 744-751. doi: 10.1016/j.nbd.2005.05.006

Ginés, S., Bosch, M., Marco, S., Gavaldà, N., Díaz-Hernández, M., Lucas, J. J., et al. (2006). Reduced expression of the TrkB receptor in Huntington's disease mouse models and in human brain. Eur. J. Neurosci. 23, 649-658. doi: 10.1111/j.14609568.2006.04590.x

Ginés, S., Paoletti, P., and Alberch, J. (2010). Impaired TrkB-mediated ERK1/2 activation in huntington disease knock-in striatal cells involves reduced p52/p46 Shc expression. J. Biol. Chem. 285, 21537-21548. doi: 10.1074/jbc.M109.084202

Gomez-Palacio-Schjetnan, A., and Escobar, M. L. (2013). Neurotrophins and synaptic plasticity. Curr. Top. Behav. Neurosci. 15, 117-136. doi: 10.1007/7854_2012_231

Gourley, S. L., Kiraly, D. D., Howell, J. L., Olausson, P., and Taylor, J. R. (2008). Acute hippocampal brain-derived neurotrophic factor restores motivational and forced swim performance after corticosterone. Biol. Psychiatry 64, 884-890. doi: 10.1016/j.biopsych.2008.06.016

Graham, R. K., Deng, Y., Slow, E. J., Haigh, B., Bissada, N., Lu, G., et al. (2006). Cleavage at the caspase-6 site is required for neuronal dysfunction and degeneration due to mutant huntingtin. Cell 125, 1179-1191. doi: 10.1016/j.cell.2006.04.026

Gray, M., Shirasaki, D. I., Cepeda, C., André, V. M., Wilburn, B., Lu, X.-H., et al. (2008). Full-length human mutant huntingtin with a stable polyglutamine repeat can elicit progressive and selective neuropathogenesis in BACHD mice. J. Neurosci. 28, 6182-6195. doi: 10.1523/JNEUROSCI.0857-08.2008

Gross, C., Santarelli, L., Brunner, D., Zhuang, X., and Hen, R. (2000). Altered fear circuits in 5-HT(1A) receptor KO mice. Biol. Psychiatry 48, 1157-1163. doi: 10.1016/S0006-3223(00)01041-6

Grote, H. E., Bull, N. D., Howard, M. L., van Dellen, A., Blakemore, C., Bartlett, P. F., et al. (2005). Cognitive disorders and neurogenesis deficits in Huntington's disease mice are rescued by fluoxetine. Eur. J. Neurosci. 22, 2081-2088. doi: 10.1111/j.1460-9568.2005.04365.x

Hackam, S., Singaraja, R., Wellington, C. L., Metzler, M., McCutcheon, K., Zhang, T., et al. (1998). The influence of huntingtin protein size on nuclear localization and cellular toxicity. J. Cell Biol. 141, 1097-1105.

Heng, M. Y., Detloff, P. J., and Albin, R. L. (2008). Rodent genetic models of Huntington disease. Neurobiol. Dis. 32, 1-9. doi: 10.1016/j.nbd.2008.06.005

Heuser, I. J., Chase, T. N., and Mouradian, M. M. (1991). The limbic-hypothalamicpituitary-adrenal axis in Huntington's disease. Biol. Psychiatry 30, 943-952.
Hickey, M. A., Gallant, K., Gross, G. G., Levine, M. S., and Chesselet, M.-F. (2005). Early behavioral deficits in R6/2 mice suitable for use in preclinical drug testing. Neurobiol. Dis. 20, 1-11. doi: 10.1016/j.nbd.2005.01.024

Hickey, M. A., Kosmalska, A., Enayati, J., Cohen, R., Zeitlin, S., Levine, M. S., et al. (2008). Extensive early motor and non-motor behavioral deficits are followed by striatal neuronal loss in knock-in Huntington's disease mice. Neuroscience 157, 280-295. doi: 10.1016/j.neuroscience.2008.08.041

Hodgson, J. G., Agopyan, N., Gutekunst, C.-A., Leavitt, B. R., LePiane, F., Singaraja, R., et al. (1999). A YAC mouse model for huntington's disease with full-length mutant huntingtin, cytoplasmic toxicity, and selective striatal neurodegeneration. Neuron 23, 181-192.

Holmes, A., Yang, R. J., Murphy, D. L., and Crawley, J. N. (2002). Evaluation of antidepressant-related behavioral responses in mice lacking the serotonin transporter. Neuropsychopharmacology 27, 914-923. doi: 10.1016/S0893133X (02)00374-3

$\mathrm{Hu}$, Y., and Russek, S. J. (2008). BDNF and the diseased nervous system: a delicate balance between adaptive and pathological processes of gene regulation. J. Neurochem. 105, 1-17. doi: 10.1111/j.1471-4159.2008.05237.x

Humbert, S., Bryson, E. A., Cordelières, F. P., Connors, N. C., Datta, S. R., Finkbeiner, S., et al. (2002). The IGF-1/Akt pathway is neuroprotective in Huntington's disease and involves Huntingtin phosphorylation by Akt. Dev. Cell. 2, 831-837. doi: 10.1016/S1534-5807(02)00188-0

Jones, M. D., and Lucki, I. (2005). Sex differences in the regulation of serotonergic transmission and behavior in 5-HT receptor knockout mice. Neuropsychopharmacology 30, 1039-1047. doi: 10.1038/sj.npp.1300664

Jongen, P. J., Reiner, W. O., and Gabreëls, F. J. (1980). Seven cases of Huntington's disease in childhood and levodopa induced improvement in the hypokineticrigid form. Clin. Neurol. Neurosurg. 82, 251-261

Julien, C. L., Thompson, J. C., Wild, S., Yardumian, P., Snowden, J. S., Turner, G., et al. (2007). Psychiatric disorders in preclinical Huntington's disease. J. Neurol. Neurosurg. Psychiatry 78, 939-943. doi: 10.1136/jnnp.2006.103309

Karishma, K. K., and Herbert, J. (2002). Dehydroepiandrosterone (DHEA) stimulates neurogenesis in the hippocampus of the rat, promotes survival of newly formed neurons and prevents corticosterone-induced suppression. Eur. J. Neurosci. 16, 445-453. doi: 10.1046/j.1460-9568.2002.02099.x

Kingma, E. M., van Duijn, E., Timman, R., van der Mast, R. C., and Roos, R. A. C. (2008). Behavioral problems in Huntington's disease using the Problem Behaviors Assessment. Gen. Hosp. Psychiatry 30, 155-161. doi: 10.1016/j.genhosppsych.2007.11.005

Klempin, F., Babu, H., De Pietri Tonelli, D., Alarcon, E., Fabel, K., and Kempermann, G. (2010). Oppositional effects of serotonin receptors 5-HT1a, 2 , and $2 \mathrm{c}$ in the regulation of adult hippocampal neurogenesis. Front. Mol. Neurosci. 3:14. doi: 10.3389/fnmol.2010.00014

Klivenyi, P., Bende, Z., Hartai, Z., Penke, Z., Nemeth, H., Toldi, J., et al. (2006). Behaviour changes in a transgenic model of Huntington's disease. Behav. Brain Res. 169, 137-141. doi: 10.1016/j.bbr.2006.01.003

Kohl, Z., Kandasamy, M., Winner, B., Aigner, R., Gross, C., Couillard-Despres, S., et al. (2007). Physical activity fails to rescue hippocampal neurogenesis deficits in the R6/2 mouse model of Huntington's disease. Brain Res. 1155, 24-33. doi: 10.1016/j.brainres.2007.04.039

Kornstein, S. G., Schatzberg, F., Thase, M. E., Yonkers, K., McCullough, J. P., Keitner, G. I., et al. (2000). Gender differences in treatment response to sertraline versus imipramine in chronic depression. Am. J. Psychiatry 157, 1445-1452. doi: 10.1176/appi.ajp.157.9.1445

Krishnan, V., Han, M.-H., Graham, D. L., Berton, O., Renthal, W., Russo, S. J., et al. (2007). Molecular adaptations underlying susceptibility and resistance to social defeat in brain reward regions. Cell 131, 391-404. doi: 10.1016/j.cell.2007. 09.018

Krogias, C., Strassburger, K., Eyding, J., Gold, R., Norra, C., Juckel, G., et al. (2011). Depression in patients with Huntington disease correlates with alterations of the brain stem raphe depicted by transcranial sonography. J. Psychiatry Neurosci. 36, 187-194. doi: 10.1503/jpn.100067

Kupfer, D. J., Frank, E., and Phillips, M. L. (2012). Major depressive disorder: new clinical, neurobiological, and treatment perspectives. Lancet 379, 1045-1055. doi: 10.1016/S0140-6736(11)60602-8

Landles, C., Sathasivam, K., Weiss, A., Woodman, B., Moffitt, H., Finkbeiner, S., et al. (2010). Proteolysis of mutant huntingtin produces an exon 1 fragment that accumulates as an aggregated protein in neuronal nuclei in Huntington disease. J. Biol. Chem. 285, 8808-8823. doi: 10.1074/jbc.M109.075028 
Lazic, S. E., Grote, H. E., Armstrong, R. J. E., Blakemore, C., Hannan, A. J., van Dellen, A., et al. (2004). Decreased hippocampal cell proliferation in R6/1 Huntington's mice. Neuroreport 15, 811-813.

Lazic, S. E., Grote, H. E., Blakemore, C., Hannan, A. J., van Dellen, A., Phillips, W., et al. (2006). Neurogenesis in the R6/1 transgenic mouse model of Huntington's disease: effects of environmental enrichment. Eur. J. Neurosci. 23, 1829-1838. doi: 10.1111/j.1460-9568.2006.04715.x

Lazo, O. M., Gonzalez, A., Ascano, M., Kuruvilla, R., and Couve, A. (2013). BDNF regulates Rab11-mediated recycling endosome dynamics to induce dendritic branching. J. Neurosci. 33, 6112-6122. doi: 10.1523/JNEUROSCI.463012.2013.BDNF

Leblhuber, F., Peichl, M., Neubauer, C., Reisecker, F., Steinparz, F. X., Windhager, E., et al. (1995). Serum dehydroepiandrosterone and cortisol measurements in Huntington's chorea. J. Neurol. Sci. 132, 76-79.

Lee, J., Duan, W., and Mattson, M. P. (2002). Evidence that brain-derived neurotrophic factor is required for basal neurogenesis and mediates, in part, the enhancement of neurogenesis by dietary restriction in the hippocampus of adult mice. J. Neurochem. 82, 1367-1375. doi: 10.1046/j.1471-4159.2002.01085.x

Levy, M. L., Cummings, J. L., Fairbanks, L. A., Masterman, D., Miller, B. L., Craig, A. H., et al. (1998). Apathy is not depression. J. Neuropsy. Clin. Neurosci. 10, 314-319.

Li, S., Gutekunst, C., Hersch, S. M., and Li, X. (1998). Interaction of HuntingtinAssociated Protein with Dynactin P150 Glued. J. Neurosci. 18, 1261-1269.

Li, X., Valencia, A., Sapp, E., Masso, N., Alexander, J., Reeves, P., et al. (2010). Aberrant Rab11-Dependent trafficking of the neuronal glutamate transporter EAAC1 causes oxidative stress and cell death in Huntington's Disease. J. Neurosci. 30, 4552- 4561. doi: 10.1523/JNEUROSCI.5865-09.2010

Li, Y., Luikart, B. W., Birnbaum, S., Chen, J., Kwon, C.-H., Kernie, S. G., et al. (2008). TrkB regulates hippocampal neurogenesis and governs sensitivity to antidepressive treatment. Neuron 59, 399-412. doi: 10.1016/j.neuron.2008.06.023

Liot, G., Zala, D., Pla, P., Mottet, G., Piel, M., and Saudou, F. (2013). Mutant Huntingtin alters retrograde transport of TrkB receptors in striatal dendrites. J. Neurosci. 33, 6298-6309. doi: 10.1523/JNEUROSCI.2033-12.2013

Lira, A., Zhou, M., Castanon, N., Ansorge, M. S., Gordon, J. A., Francis, J. H., et al. (2003). Altered depression-related behaviors and functional changes in the dorsal raphe nucleus of serotonin transporter-deficient mice. Biol. Psychiatry 54, 960-971. doi: 10.1016/S0006-3223(03)00696-6

Luellen, B. A., Bianco, L. E., Schneider, L. M., and Andrews, A. M. (2007). Reduced brain-derived neurotrophic factor is associated with a loss of serotonergic innervation in the hippocampus of aging mice. Genes. Brain. Behav. 6, 482-490. doi: 10.1111/j.1601-183X.2006.00279.x

Lyons, W. E., Mamounas, L. A., Ricaurte, G. A., Coppola, V., Reid, S. W., Bora, S. H., et al. (1999). Brain-derived neurotrophic factor-deficient mice develop aggressiveness and hyperphagia in conjunction with brain serotonergic abnormalities. Proc. Natl. Acad. Sci. U.S.A. 96, 15239-15344.

Madhav, T. R., Pei, Q., and Zetterström, T. S. (2001). Serotonergic cells of the rat raphe nuclei express mRNA of tyrosine kinase $\mathrm{B}$ (trkB), the high-affinity receptor for brain derived neurotrophic factor (BDNF). Mol. Brain Res. 93, 56-63. doi: 10.1016/S0169-328X(01)00183-8

Malberg, J. E., and Blendy, J. A. (2005). Antidepressant action: to the nucleus and beyond. Trends Pharmacol. Sci. 26, 631-638. doi: 10.1016/j.tips.2005.10.005

Mangiarini, L., Sathasivam, K., Seller, M., Cozens, B., Harper, A., Hetherington, C., et al. (1996). Exon 1 of the HD gene with an expanded CAG repeat is sufficient to cause a progressive neurological phenotype in transgenic mice. Cell 87, 493-506.

Marshall, J., White, K., Weaver, M., Flury Wetherill, L., Hui, S., Stout, J. C., et al. (2007). Specific psychiatric manifestations among preclinical Huntington disease mutation carriers. Arch. Neurol. 64, 116-121. doi: 10.1001/archneur.64.1.116

Mayorga, A. J., Dalvi, A., Page, M. E., Zimov-Levinson, S., and Hen, R. (2001). Antidepressant-Like Behavioral Effects in 5HTR1A and 5HTR1B mutant mice. J. Pharmacol. Exp. Ther. 298, 1101-1107.

McGuire, J. R., Rong, J., Li, S.-H., and Li, X.-J. (2006). Interaction of Huntingtinassociated protein-1 with kinesin light chain: implications in intracellular trafficking in neurons. J. Biol. Chem. 281, 3552-3559. doi: 10.1074/jbc.M5098 06200

Menalled, L., El-Khodor, B. F., Patry, M., Suárez-Fariñas, M., Orenstein, S. J., Zahasky, B., et al. (2009). Systematic behavioral evaluation of Huntington's disease transgenic and knock-in mouse models. Neurobiol. Dis. 35, 319-336. doi: 10.1016/j.nbd.2009.05.007

Mendez-David, I., David, D. J., Darcet, F., Wu, V. W., Kerdine-Romer, S., Gardier, A. M., et al. (2014). Rapid anxiolytic effect of 5-HT4 receptor agonist are mediated by a neurogenesis-independent mechanism. Neuropsychopharmacology 39, 1366-1378. doi: 10.1038/npp.2013.332

Mestre, T. A. and Ferreira, J. J. (2012). An evidence-based approach in the treatment of Huntington's disease. Parkinsonism Relat. Disord. 18, 316-320. doi: 10.1016/j.parkreldis.2011.10.021

Miller, B. H., Schultz, L. E., Gulati, A., Su, A. I., and Pletcher, M. T. (2010). Phenotypic characterization of a genetically diverse panel of mice for behavioral despair and anxiety. PLoS ONE 5:e14458. doi: 10.1371/journal.pone. 0014458

Milnerwood, A. J., and Raymond, L. A. (2007). Corticostriatal synaptic function in mouse models of Huntington's disease: early effects of huntingtin repeat length and protein load. J. Physiol. 585, 817-831. doi: 10.1113/jphysiol.2007. 142448

Monteggia, L. M., Barrot, M., Powell, C. M., Berton, O., Galanis, V., Gemelli, T., et al. (2004). Essential role of brain-derived neurotrophic factor in adult hippocampal function. Proc. Natl. Acad. Sci. U.S.A. 101, 10827-10832. doi: 10.1073/pnas.0402141101

Monteggia, L. M., Luikart, B., Barrot, M., Theobold, D., Malkovska, I., Nef, S., et al. (2007). Brain-Derived neurotrophic factor conditional knockouts show gender differences in depression-related behaviors. Biol. Psychiatry 187-197. doi: 10.1016/j.biopsych.2006.03.021

Mozhui, K., Karlsson, R.-M., Kash, T. L., Ihne, J., Norcross, M., Patel, S., et al. (2010). Strain differences in stress responsivity are associated with divergent amygdala gene expression and glutamate-mediated neuronal excitability. J. Neurosci. 30, 5357-5367. doi: 10.1523/JNEUROSCI.5017-09.2010

Murray, F., Smith, D. W., and Hutson, P. H. (2008). Chronic low dose corticosterone exposure decreased hippocampal cell proliferation, volume and induced anxiety and depression like behaviors in mice. Eur. J. Pharmacol. 583, 115-127. doi: 10.1016/j.ejphar.2008.01.014

Nasir, J., Floresco, S. B., O’Kusky, J. R., Diewert, J. M., Richman, J., Zeisler, A., et al. (1995). Targeted disruption of Huntington's disease results in embryonic lethality and behavioral and morphological consequences in heterozygotes. Cell 81, 811-823.

Naver, B., Stub, C., Møller, M., Fenger, K., Hansen, A. K., Hasholt, L., et al. (2003). Molecular and behavioral analysis of the $\mathrm{r} 6 / 1$ huntington's disease transgenic mouse. Neuroscience 122, 1049-1057. doi: 10.1016/j.neuroscience.2003.08.053

Nestler, E. J., Barrot, M., Dileone, R. J., Eisch, A. J., Gold, S. J., and Monteggia, L. M. (2002). Neurobiology of depression review. Neuron 34, 13-25. doi: 10.1016/S0896-6273(02)00653-0

Nithianantharajah, J., Barkus, C., Murphy, M., and Hannan, A. J. (2008). Geneenvironment interactions modulating cognitive function and molecular correlates of synaptic plasticity in Huntington's disease transgenic mice. Neurobiol. Dis. 29, 490-504. doi: 10.1016/j.nbd.2007.11.006

Novak, M. J. U., and Tabrizi, S. J. (2011). Huntington's disease: clinical presentation and treatment. Int. Rev. Neurobiol. 98, 297-323. doi: 10.1016/B978-0-12381328-2.00013-4

Orvoen, S., Pla, P., Gardier, A. M., Saudou, F., and David, D. J. (2012). Huntington's disease knock-in male mice show specific anxiety-like behavior and altered neuronal maturation. Neurosci. Lett. 507, 127-132. doi: 10.1016/j.neulet.2011.11.063

Page, M. E., Detke, M. J., Dalvi, A., Kirby, L. G., and Lucki, I. (1999). Serotonergic mediation of the effects of fluoxetine, but not desipramine, in the rat forced swimming test. Psychopharmacology 147, 162-167

Pang, T. Y. C., Stam, N. C., Nithianantharajah, J., Howard, M. L., and Hannan, A. J. (2006). Differential effects of voluntary physical exercise on behavioral and brain-derived neurotrophic factor expression deficits in Huntington's disease transgenic mice. Neuroscience 141, 569-584. doi: 10.1016/j.neuroscience.2006.04.013

Pang, T. Y., Du, X., Zajac, M. S., Howard, M. L., and Hannan, A. J. (2009). Altered serotonin receptor expression is associated with depression-related behavior in the R6/1 transgenic mouse model of Huntington's disease. Hum. Mol. Genet. 18, 753-766. doi: 10.1093/hmg/ddn385

Paulsen, J. S. (2011). Cognitive impairment in huntington disease: diagnosis and treatment. Curr. Neurol. Neurosci. Rep. 11, 474-483. doi: 10.1007/s11910-0110215-x 
Paulsen, J. S., Nehl, C., Hoth, K. F., Kanz, J. E., Benjamin, M., Conybeare, R., et al. (2005). Depression and Stages of Huntington's Disease. J. Neuropsychiatr. 496502. doi: 10.1176/appi.neuropsych.17.4.496

Peinemann, A., Schuller, S., Pohl, C., Jahn, T., Weindl, A., and Kassubek, J. (2005). Executive dysfunction in early stages of Huntington's disease is associated with striatal and insular atrophy: a neuropsychological and voxel-based morphometric study. J. Neurol. Sci. 239, 11-19. doi: 10.1016/j.jns.2005.07.007

Peng, Q., Masuda, N., Jiang, M., Li, Q., Zhao, M., Ross, C. A., et al. (2008). The antidepressant sertraline improves the phenotype, promotes neurogenesis and increases BDNF levels in the R6/2 Huntington's disease mouse model. Exp. Neurol. 210, 154-163. doi: 10.1016/j.expneurol.2007.10.015

Phillips, W., Morton, A. J., and Barker, R. A. (2005). Abnormalities of neurogenesis in the R6/2 mouse model of Huntington's disease are attributable to the in vivo microenvironment. J. Neurosci. 25, 11564-11576. doi: 10.1523/JNEUROSCI.3796-05.2005

Pineda, J. R., Canals, J. M., Bosch, M., Adell, A., Mengod, G., Artigas, F., et al. (2005). Brain-derived neurotrophic factor modulate dopaminergic deficits in a transgenic mouse model of Huntington's disease. J. Neurochem. 93, 1057-1068. doi: 10.1111/j.1471-4159.2005.03047.x

Pla, P., Orvoen, S., Benstaali, C., Dodier, S., Gardier, A. M., David, D. J., et al. (2013). Huntingtin acts non cell-autonomously on hippocampal neurogenesis and controls anxiety-related behaviors in adult mouse. PLoS ONE 8:e73902. doi: 10.1371/journal.pone.0073902

Pouladi, M. A., Graham, R. K., Karasinska, J. M., Xie, Y., Santos, R. D., Petersén, A., et al. (2009). Prevention of depressive behavior in the YAC128 mouse model of Huntington disease by mutation at residue 586 of huntingtin. Brain 132, 919-932. doi: 10.1093/brain/awp006

Pouladi, M. A., Morton, A. J., and Hayden, M. R. (2013). Choosing an animal model for the study of Huntington's disease. Nat. Rev. Neurosci. 14, 708-721. doi: $10.1038 / \mathrm{nrn} 3570$

Pouladi, M. A., Stanek, L. M., Xie, Y., Franciosi, S., Southwell, A. L., Deng, Y., et al. (2012). Marked differences in neurochemistry and aggregates despite similar behavioral and neuropathological features of Huntington disease in the full-length BACHD and YAC128 mice. Hum. Mol. Genet. 21, 2219-2232. doi: 10.1093/hmg/dds037

Quesseveur, G., David, D. J., Gaillard, M. C., Pla, P., Wu, M. V., Nguyen, H. T., et al. (2013). BDNF overexpression in mouse hippocampal astrocytes promotes local neurogenesis and elicits anxiolytic-like activities. Transl. Psychiatry 3, e253. doi: $10.1038 /$ tp. 2013.30

Rainnie, D. G. (1999). Serotonergic modulation of neurotransmission in the rat basolateral amygdala. J. Neurophysiol. 82, 69-85.

Rangone, H., Poizat, G., Troncoso, J., Ross, C. A., MacDonald, M. E., Saudou, F., et al. (2004). The serum and glucocorticoid-induced kinase SGK inhibits mutant huntingtin-induced toxicity by phosphorylating serine 421 of huntingtin. Eur. J. Neurosci. 19, 273-279. doi: 10.1111/j.0953-816X.2003.03131.x

Rantamäki, T., Hendolin, P., Kankaanpää, A., Mijatovic, J., Piepponen, P., Domenici, E., et al. (2007). Pharmacologically diverse antidepressants rapidly activate brain-derived neurotrophic factor receptor TrkB and induce phospholipase-Cgamma signaling pathways in mouse brain. Neuropsychopharmacology 32, 2152-2162. doi: 10.1038/sj.npp.1301345

Reedeker, W., van der Mast, R. C., Giltay, E. J., Kooistra, T. A., Roos, R. A., and van Duijn, E. (2012). Psychiatric disorders in Huntington's disease: a 2-year followup study. Psychosomatics 53, 220-229. doi: 10.1016/j.psym.2011.12.010

Renoir, T., Pang, T. Y. C., Zajac, M. S., Chan, G., Du, X., Leang, L., et al. (2012). Treatment of depressive-like behavior in Huntington's disease mice by chronic sertraline and exercise. Br. J. Pharmacol. 165, 1375-1389. doi: 10.1111/j.14765381.2011.01567.x

Renoir, T., Zajac, M. S., Du, X., Pang, T. Y., Leang, L., Chevarin, C., et al. (2011). Sexually dimorphic serotonergic dysfunction in a mouse model of Huntington's Disease and depression. PLoS ONE 6:e22133. doi: 10.1371/journal.pone. 0022133

Huntington Collaborative Research Group (1993). A novel gene containing a trinucleotide that is expanded and unstable on huntington's disease chromosomes. Cell 72, 971-983.

Richards, G., Messer, J., Waldvogel, H. J., Gibbons, H. M., Dragunow, M., Faull, R. L. M., et al. (2011). Up-regulation of the isoenzymes MAO-A and MAO-B in the human basal ganglia and pons in Huntington's disease revealed by quantitative enzyme radioautography. Brain Res. 1370, 204-214. doi: 10.1016/j.brainres.2010.11.020
Rong, J., Li, S., Sheng, G., Wu, M., Coblitz, B., Li, M., et al. (2007). 14-3-3 protein interacts with Huntingtin-associated protein 1 and regulates its trafficking. J. Biol. Chem. 282, 4748-4756. doi: 10.1074/jbc.M609057200

Rosenblatt, A. (2007). Neuropsychiatry of HD. Dialogues Clin. Neurosci. 9, 191-197. Rowe, K. C., Paulsen, J. S., Langbehn, D. R., Wang, C., Mills, J., Beglinger, L. J., et al. (2012). Patterns of serotonergic antidepressant usage in prodromal Huntington disease. Psychiatry Res. 196, 309-314. doi: 10.1016/j.psychres.2011. 09.005

Rubinow, D. R., Roca, C. A., Schmidt, P. J., Danaceau, M. A., Putnam, K., Cizza, G., et al. (2005). Testosterone suppression of CRH-stimulated cortisol in men. Neuropsychopharmacology 30, 1906-1912. doi: 10.1038/sj.npp.1300742

Rudolph, U., and Möhler, H. (2014). GABAA receptor subtypes: therapeutic potential in down syndrome, affective disorders, schizophrenia, and autism. Annu. Rev. Pharmacol. Toxicol. 54, 483-507. doi: 10.1146/annurev-pharmtox-011613135947

Saarelainen, T., Hendolin, P., Lucas, G., Koponen, E., Sairanen, M., Macdonald, E., et al. (2003). Activation of the TrkB neurotrophin receptor is induced by antidepressant drugs and is required for antidepressant-induced behavioral effects. $J$. Neurosci. 23, 349-357.

Sairanen, M., Lucas, G., Ernfors, P., Castrén, M., and Castrén, E. (2005). Brainderived neurotrophic factor and antidepressant drugs have different but coordinated effects on neuronal turnover, proliferation, and survival in the adult dentate gyrus. J. Neurosci. 25, 1089-1094. doi: 10.1523/JNEUROSCI.374104.2005

Samuels, B., and Hen, R. (2011). Neurogenesis and affective disorders. Eur. J. Neurosci. 33, 1152-1159. doi: 10.1111/j.1460-9568.2011.07614.x

Saydoff, J. A., Garcia, R. A. G., Browne, S. E., Liu, L., Sheng, J., Brenneman, D., Hu, Z., et al. (2006). Oral uridine pro-drug PN401 is neuroprotective in the R6/2 and N171-82Q mouse models of Huntington's disease. Neurobiol. Dis. 24, 455-465. doi: 10.1016/j.nbd.2006.08.011

Schilling, G., Becher, M. W., Sharp, A. H., Jinnah, H. A., Duan, K., Kotzuk, J. A., et al. (1999). Intranuclear inclusions and neuritic aggregates in transgenic mice expressing a mutant N-terminal fragment of huntingtin. Hum. Mol. Genet. 8, 397-407. doi: $10.1093 / \mathrm{hmg} / 8.3 .397$

Seo, H., and Sonntag, K. C., Isacson, O. (2004). Generalized brain and skin proteasome inhibition in Huntington's disease. Ann. Neurol. 56, 319-328. doi: 10.1002/ana.20207

Shirbin, C. A., Chua, P., Churchyard, A., Lowndes, G., Hannan, A. J., Pang, T. Y., et al. (2013). Cortisol and depression in pre-diagnosed and early stage Huntington's disease. Psychoneuroendocrinology 38, 2439-2447. doi: 10.1016/j. psyneuen.2012.10.020

Simmons, D. A., Rex, C. S., Palmer, L., Pandyarajan, V., Fedulov, V., Gall, C. M., et al. (2009). Up-regulating BDNF with an ampakine rescues synaptic plasticity and memory in Huntington's disease knockin mice. Proc. Natl. Acad. Sci. U.S.A. 106, 4906-4911. doi: 10.1073/pnas.0811228106

Simpson, J. M., Gil-Mohapel, J., Pouladi, M. A., Ghilan, M., Xie, Y., Hayden, M. R., et al. (2011). Altered adult hippocampal neurogenesis in the YAC128 transgenic mouse model of Huntington disease. Neurobiol. Dis. 41, 249-260. doi: 10.1016/j.nbd.2010.09.012

Smith, M. M., Mills, J. A., Epping, E. A., Westervelt, H., Paulsen, J. S., and PREDICT -HD Investigators of the Huntington Study Group. (2012). Depressive symptom severity is related to poorer cognitive performance in Prodromal Huntington Disease. Neuropsychology 26, 664-669. doi: 10.1037/a0029218

Steward, L. J., Bufton, K. E., Hopkins, P. C., Davies, W. E., and Barnes, N. M. (1993). Reduced levels of 5-HT3 receptor recognition sites in the putamen of patients with Huntington's disease. Eur. J. Pharmacol. 242, 137-143.

Strand, A. D., Baguet, Z. C., Aragaki, A. K., Holmans, P., Yang, L., Cleren, C., et al. (2007). Expression profiling of Huntington's disease models suggests that brainderived neurotrophic factor depletion plays a major role in striatal degeneration. J. Neurosci. 27, 11758-11768. doi: 10.1523/JNEUROSCI.2461-07.2007

Sullivan, F. R., Bird, E. D., Alpay, M., and Cha, J. H. (2001). Remotivation therapy and Huntington's disease. J. Neurosci. Nurs. 33, 136-142.

Thompson, J. C., Harris, J., Sollom, A. C., Stopford, C. L., Howard, E., Snowden, J. S., et al. (2012). Longitudinal evaluation of neuropsychiatric symptoms in Huntington's disease. J. Neuropsychiatry Clin. Neurosci. 24, 53-60. doi: 10.1176/appi.neuropsych.11030057

Trivedi, M. H., and Greer, T. L. (2014). Cognitive dysfunction in unipolar depression: implications for treatment. J. Affect. Dis. 152, 19-27. doi: 10.1016/j.jad.2013.09.012 
Twelvetrees, A. E., Yuen, E. Y., Arancibia-Carcamo, I. L., MacAskill, A. F., Rostaing, P., Lumb, M. J., et al. (2010). Delivery of GABAARs to synapses is mediated by HAP1-KIF5 and disrupted by mutant huntingtin. Neuron 65, 53-65. doi: 10.1016/j.neuron.2009.12.007

Tyler, W. J., and Pozzo-Miller, L. (2003). Miniature synaptic transmission and BDNF modulate dendritic spine growth and form in rat CA1 neurones. J. Physiol. 553, 497-509. doi: 10.1113/jphysiol.2003.052639

Van Duijn, E., Kingma, E. M., Timman, R., Zitman, F. G., Tibben, A., Roos, R. A. C., et al. (2008). Cross-sectional study on prevalences of psychiatric disorders in mutation carriers of Huntington's disease compared with mutation-negative first degree relatives. J. Clin. Psychiatry 69, 1804-1810.

Van Duijn, E., Selis, M. A., Giltay, E. J., Zitman, F. G., Roos, R. A. C., van Pelt, H., et al. (2010). Hypothalamic-pituitary-adrenal axis functioning in Huntington's disease mutation carriers compared with mutation-negative first-degree controls. Brain Res. Bull. 83, 232-237. doi: 10.1016/j.brainresbull.2010.08.006

Von Bohlen und Halbach, O., Krause, S., Medina, D., Sciarretta, C., Minichiello, L., and Unsicker, K. (2006). Regional- and age-dependent reduction in trkB receptor expression in the hippocampus is associated with altered spine morphologies. Biol. Psychiatry 59, 793-800. doi: 10.1016/j.biopsych.2005.08.025

Von Bohlen und Halbach, O., Minichiello, L., and Unsicker, K. (2008). TrkB but not trkC receptors are necessary for postnatal maintenance of hippocampal spines. Neurobiol. Aging 29, 1247-1255. doi: 10.1016/j.neurobiolaging.2007.02.028

Waeber, C., and Palacios, J. M. (1989). Serotonin-1 receptor binding sites in the human basal ganglia are decreased in Huntington's chorea but not in Parkinson's disease: a quantitative in vitro autoradiography study. Neuroscience 32, 337-347.

Walker, F. O. (2007). Huntington's disease. Lancet 369, 218-228. doi: 10.1016/S0140-6736(07)60111-1

Walker, T. L., Turnbull, G. W., Mackay, E. W., Hannan, A. J., and Bartlett, P. F. (2011). The latent stem cell population is retained in the hippocampus of transgenic Huntington's disease mice but not wild-type mice. PLOS ONE 6:e18153. doi: 10.1371/journal.pone.0018153

Wang, H., Chen, X., Li, Y., Tang, T.-S., and Bezprozvanny, I. (2010). Tetrabenazine is neuroprotective in Huntington's disease mice. Mol. Neurodegener. 5, 18. doi: 10.1186/1750-1326-5-18

Wong, E. H., Reynolds, G. P., Bonhaus, D. W., Hsu, S., and Eglen, R. M. (1996). Characterization of 3HGR 113808 binding to 5-HT4 receptors in brain tissues from patients with neurodegenerative disorders. Behav. Brain Res. 73, 249-252.

Xia, L., Deloménie, C., David, I., Rainer, Q., Marouard, M., Delacroix, H., et al. (2012). Ventral hippocampal molecular pathways and impaired neurogenesis associated with 5-HT 1A and 5-HT 1B receptors disruption in mice. Neurosci. Lett. 521, 20-25. doi: 10.1016/j.neulet.2012.05.046

Xie, Y., Hayden, M. R., and Xu, B. (2010). BDNF overexpression in the forebrain rescues Huntington's disease phenotypes in YAC128 mice. J. Neurosci. 30, 14708-14718. doi: 10.1523/JNEUROSCI.1637-10.2010

Yohrling, G. J. IV., Jiang, G. C. T., DeJohn, M. M., Robertson, D. J., Vrana, K. E., and Cha, J. H. J. (2002). Inhibition of tryptophan hydroxylase activity and decreased 5-HT 1A receptor binding in a mouse model of Huntington's disease. J. Neurochem. 82, 1416-1423. doi: 10.1046/j.1471-4159.2002.01084.x

Young, A. B., Greenamyre, J. T., Hollingsworth, Z., Albin, R., D’Amato, C., Shoulson, I. R. A., et al. (1988). NMDA Receptor Losses in Putamen from Patients with Huntington's Disease. Science 241, 981-983.
Yu, H., and Chen, Z. (2011). The role of BDNF in depression on the basis of its location in the neural circuitry. Acta Pharmacol. Sin. 32, 3-11. doi: 10.1038/aps.2010.184

Yuen, E. Y., Wei, J., Zhong, P., and Yan, Z. (2012). Disrupted GABAAR trafficking and synaptic inhibition in a mouse model of Huntington's disease. Neurobiol. Dis. 46, 497-502. doi: 10.1016/j.nbd.2012.02.015

Zajac, M. S., Pang, T. Y. C., Wong, N., Weinrich, B., Leang, L. S. K., Craig, J. M., et al. (2010). Wheel running and environmental enrichment differentially modify exon-specific BDNF expression in the hippocampus of wild-type and pre-motor symptomatic male and female Huntington's disease mice. Hippocampus 20, 621-636. doi: 10.1002/hipo.20658

Zala, D., Colin, E., Rangone, H., Liot, G., Humbert, S., and Saudou, F. (2008). Phosphorylation of mutant huntingtin at S421 restores anterograde and retrograde transport in neurons. Hum. Mol. Genet. 17, 3837-3846. doi: 10.1093/hmg/ddn281

Zeitlin, S., Liu, J. P., Chapman, D. L., Papaioannou, V. E., and Efstratiadis, A. (1995). Increased apoptosis and early embryonic lethality in mice nullizygous for the Huntington's disease gene homologue. Nat. Genet. 11, 155-163.

Zuccato, C., Ciammola, A., Rigamonti, D., Leavitt, B. R., Goffredo, D., Conti, L., et al. (2001). Loss of huntingtin-mediated BDNF gene transcription in Huntington's disease. Science 293, 493-498. doi: 10.1126/science.1059581

Zuccato, C., Liber, D., Ramos, C., Tarditi, A., Rigamonti, D., Tartari, M., et al. (2005). Progressive loss of BDNF in a mouse model of Huntington's disease and rescue by BDNF delivery. Pharmacol. Res. 52, 133-139. doi: 10.1016/j.phrs.2005.01.001

Zuccato, C., Marullo, M., Conforti, P., MacDonald, M. E., Tartari, M., and Cattaneo, E. (2008). Systematic assessment of BDNF and its receptor levels in human cortices affected by Huntington's disease. Brain Pathol. 18, 225-238. doi: 10.1111/j.1750-3639.2007.00111.x

Zuccato, C., Tartari, M., Crotti, A., Goffredo, D., Valenza, M., Conti, L., et al. (2003). Huntingtin interacts with REST/NRSF to modulate the transcription of NRSE-controlled neuronal genes. Nat. Genet. 35, 76-83. doi: 10.1038/ ng1219

Zuccato, C., Valenza, M., and Cattaneo, E. (2010). Molecular Mechanisms and Potential Therapeutical Targets in Huntington's Disease. Physiol. Rev. 905-981. doi: 10.1152/physrev.00041.2009

Conflict of Interest Statement: The authors declare that the research was conducted in the absence of any commercial or financial relationships that could be construed as a potential conflict of interest.

Received: 25 February 2014; accepted: 03 April 2014; published online: 23 April 2014. Citation: Pla P, Orvoen S, Saudou F, David DJ and Humbert S (2014) Mood disorders in Huntington's disease: from behavior to cellular and molecular mechanisms. Front. Behav. Neurosci. 8:135. doi: 10.3389/fnbeh.2014.00135

This article was submitted to the journal Frontiers in Behavioral Neuroscience.

Copyright (c) 2014 Pla, Orvoen, Saudou, David and Humbert. This is an openaccess article distributed under the terms of the Creative Commons Attribution License (CC BY). The use, distribution or reproduction in other forums is permitted, provided the original author(s) or licensor are credited and that the original publication in this journal is cited, in accordance with accepted academic practice. No use, distribution or reproduction is permitted which does not comply with these terms. 